\title{
Exosome-Based Cell-Cell Communication in the Tumor Microenvironment
}

\section{OPEN ACCESS}

Edited by:

William Curtis Hines,

University of New Mexico School of

Medicine, United States

Reviewed by:

Lasse Dahl Ejby Jensen, Linköping University, Sweden

Leonard C. Edelstein,

Thomas Jefferson University,

United States

*Correspondence:

Bruno Costa-Silva

bruno.costa-silva@

research.fchampalimaud.org

${ }^{\dagger}$ These authors have contributed equally to this work.

Specialty section:

This article was submitted to

Molecular Medicine,

a section of the journal

Frontiers in Cell and Developmental

Biology

Received: 06 November 2017

Accepted: 06 February 2018

Published: 20 February 2018

Citation:

Maia J, Caja S, Strano Moraes MC, Couto N and Costa-Silva B (2018)

Exosome-Based Cell-Cell Communication in the Tumor Microenvironment.

Front. Cell Dev. Biol. 6:18. doi: 10.3389/fcell.2018.00018

\section{Joana Maia ${ }^{\dagger}$, Sergio Caja ${ }^{\dagger}$, Maria Carolina Strano Moraes ${ }^{\dagger}$, Nuno Couto and Bruno Costa-Silva*}

Systems Oncology Group, Champalimaud Research, Champalimaud Foundation, Lisbon, Portugal

Tumors are not isolated entities, but complex systemic networks involving cell-cell communication between transformed and non-transformed cells. The milieu created by tumor-associated cells may either support or halt tumor progression. In addition to cell-cell contact, cells communicate through secreted factors via a highly complex system involving characteristics such as ligand concentration, receptor expression and integration of diverse signaling pathways. Of these, extracellular vesicles, such as exosomes, are emerging as novel cell-cell communication mediators in physiological and pathological scenarios. Exosomes, membrane vesicles of endocytic origin released by all cells (both healthy and diseased), ranging in size from 30 to $150 \mathrm{~nm}$, transport all the main biomolecules, including lipids, proteins, DNAs, messenger RNAs and microRNA, and perform intercellular transfer of components, locally and systemically. By acting not only in tumor cells, but also in tumor-associated cells such as fibroblasts, endothelium, leukocytes and progenitor cells, tumor- and non-tumor cells-derived exosomes have emerged as new players in tumor growth and invasion, tumor-associated angiogenesis, tissue inflammation and immunologic remodeling. In addition, due to their property of carrying molecules from their cell of origin to the peripheral circulation, exosomes have been increasingly studied as sources of tumor biomarkers in liquid biopsies. Here we review the current literature on the participation of exosomes in the communication between tumor and tumor-associated cells, highlighting the role of this process in the setup of tumor microenvironments that modulate tumor initiation and metastasis.

Keywords: exosomes, cancer, tumor microenvironment, extracellular vesicles (EVs), cell-cell communication

\section{INTRODUCTION}

The tumor microenvironment is anything but simple. Be it the primary or the metastatic tumor, its complex and heterogeneous microenvironment is comprised of a network of both cellular and acellular constituents. While the former consists of tumor cells and diverse non-transformed cells, such as cancer-associated fibroblasts, macrophages, and endothelial cells, the latter is formed by secreted factors and components of the extracellular matrix (ECM). In its intricacy, the tumor microenvironment has emerged to be a key modulator of tumor progression by providing inhibitory or stimulatory growth signals (Bissell and Hines, 2011).

Interactions amongst neighboring cells in the primary tumor are essential for tumor growth and development, and besides direct cell-cell contact, intercellular communication also happens 
through a complex system involving secreted factors. Besides local cell-to-cell communication, secreted factors play a key role in the interaction amongst cells located far apart from each other (Becker et al., 2016; Fu et al., 2016; Kalluri, 2016; Peinado et al., 2017). In the group of secreted factors, we will here focus on the roles of exosomes in setting up and modifying tumor microenvironments.

The study of exosomes and other extracellular vesicles (EVs) is a relatively new field of research that picked up steam in the last couple of decades. The first indication of the existence of EVs came in 1946, when Chargaff and West showed that a platelet-free plasma fraction maintained clotting properties, which was diminished after a high-speed ultracentrifugation that pelleted a particulate fraction with coagulatory activity (Chargaff and West, 1946). After two more studies in the 1950's on the role of alike fractions in promotion of coagulation (Hougie, 1955; O’Brien, 1955), in 1967 Peter Wolf published his seminal work showing by electron microscopy the "coagulant material in minute particulate form" pelleted by ultracentrifugation. Wolf called these lipid rich particles originated from platelets "plateletdust," and also suggested that these lipid particles might be normally liberated in circulating blood (Wolf, 1967). Decades later, platelet-derived microparticles were in fact shown to be the most abundant extracellular vesicle population in peripheral blood (Zmigrodzka et al., 2016). In the early 1980's, two articles were published reporting that these particles could also be produced by tumor cells (Dvorak et al., 1981, 1983). Later, in 1987, while studying reticulocyte maturation, Johnstone and colleagues introduced for the first time the term "exosomes" to describe these particles (Johnstone et al., 1987). By then, exosomes were commonly seen as "trashbags" for excreting cellular components, but in 1998 Sebastian Amigorena's group proposed a role for exosomes in the communication between cells of the immune system, thus making exosome's debut as a mediator of cell-cell communication (Zitvogel et al., 1998). Few years after, in 2001, it was shown that platelet-derived EV could transfer antigens like CD41 from platelets to the cell membranes of CD34+ hematopoietic stem-progenitor cells, demonstrating the ability of EVs to horizontally transfer information (JanowskaWieczorek et al., 2001; Figure 1A). Platelet-derived EV were also shown to induce tumor chemotaxis, proliferation, invasion and expression of angiogenic factors, contributing to the formation of distant metastasis (Janowska-Wieczorek et al., 2005, 2006; Toth et al., 2008; Dashevsky et al., 2009). In addition, they have been shown promote thrombus formation and contribute to metastasis (Falanga et al., 2003), being plasmatic levels of these EVs associated aggressiveness, prognosis and survival of oncologic patients (Kim et al., 2003; Helley et al., 2009; Italiano et al., 2010; Voloshin et al., 2014).

Being still an immature scientific field, EVs' research still faces several basic challenges. The nomenclature of distinct types of EVs, the lack of good established markers and the technical difficulties and heterogeneity of isolation protocols, for instance, have in the last few years been subject of extensive evaluations and debates. In an attempt to improve standardization in the field, the International Society for Extracellular Vesicles recently released guidelines for the analysis of EVs and the reporting of the results (Lotvall et al., 2014), a standardization initiative followed by others, such as the EV-TRACK Consortium (EV-TRACK Consortium et al., 2017). EVs can be classified according to size and cellular origin (endosome- or plasma membrane-derived). Differently from larger EVs, which are released directly from the plasma membrane of both living and dying cells, such as microvesicles and apoptotic bodies, and from vesicular artifacts composed of disrupted membrane fragments spontaneously released by cells undergoing necrosis, known as microsomes (Witwer et al., 2013), exosomes are small EVs, ranging in size from 30 to $150 \mathrm{~nm}$, with a multivesicular endosomal origin actively secreted by all cell types upon fusion of Multivesicular Bodies with the plasma membrane (Becker et al., 2016; Kalluri, 2016). However, most present-day EV's isolation protocols do not discriminate EVs according to their origin, and only recently Kowal and colleagues showed that only the subpopulation bearing the three Tetraspanins CD9, CD63, and CD81 corresponds to endosome-derived exosomes. Another source of confusion is the fact that current isolation protocols provide enriched fractions of EVs, but not pure fractions (Kowal et al., 2016). Thus, many studies to date consider small vesicles as exosomes regardless of cellular origin, and for the purposes of this review we do the same. Also, various nomenclatures have been used to describe small EVs over the years, and for the sake of clarity and according to the protocols the authors used for $\mathrm{EV}$ isolation we will call these small EVs exosomes, even when authors use other terms to refer to these vesicles.

Although not yet completely characterized, the process of exosomes biogenesis and release to the extracellular microenvironment relies on several energy-dependent active steps mediated by, for instance, SNAREs and Rabs and Ras GTPases (Pfeffer, 2007). During this process, exosomes are packed with proteins, lipids, DNAs, messenger RNAs (mRNAs), microRNAs (miRNA) and other non-coding RNAs (Becker et al., 2016; Figure 1B). As in other scenarios of cellular stress, including hypoxia and ER stress, exosomes production and composition has been described as markedly affected in oncologic settings, where the role of exosomes as mediators of cell-to-cell communication has been broadly studied. Exosomes' concentration is frequently higher in the blood of cancer patients when compared with healthy control human blood, and the cargo of exosomes can change according to the patient's health status (Kalluri, 2016). Here we will discuss the anti- and pro-tumorigenic effects of tumor and non-tumor cells-derived exosomes in tumorigenic and metastatic processes, focusing on how exosomes mediate interactions amongst tumor cells, leukocytes, fibroblasts, tumor-associated vasculature, and stem/progenitor cells relevant to the tumor microenvironment.

\section{EXOSOMES IN TUMOR-TUMOR COMMUNICATION}

The proliferation of tumor cells, a process indispensable for cancer progression, relies on soluble growth factors. As mentioned above, cells also convey information to the microenvironment through molecules packed in exosomes and 


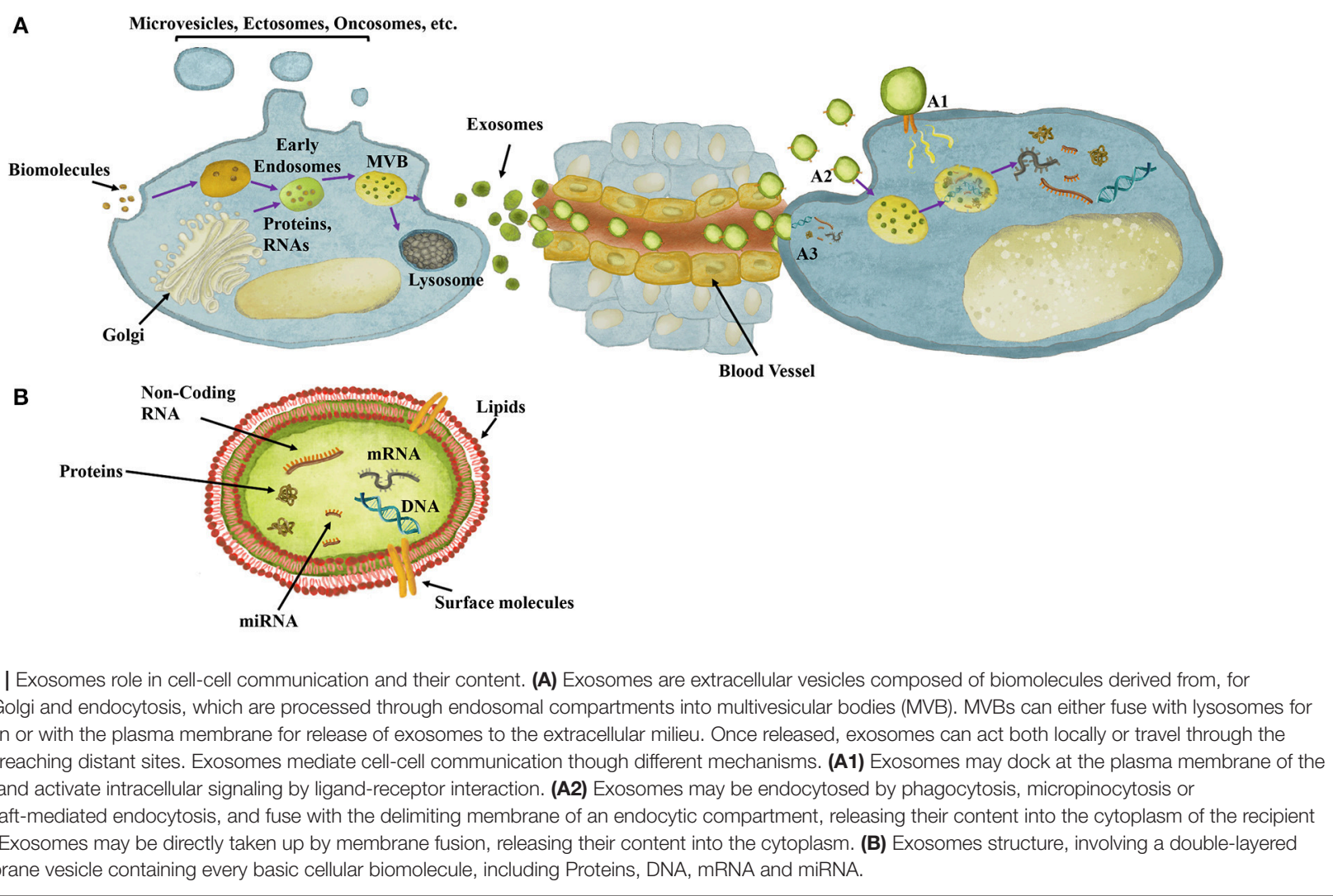

other EVs through complex signaling networks that are only beginning to be unveiled. Studies involving several distinct cancer cells showed that tumor-derived exosomes can induce tumor cell proliferation. For example, an autocrine induction of cellular proliferation was observed in chronic myeloid leukemia (Raimondo et al., 2015) and in human gastric cancer (Qu et al., 2009; Pan et al., 2017) through, for instance, the phosphatidylinositol 3-kinase/protein kinase B (PI3K/AKT) and MAPK/ERK signaling pathways (Qu et al., 2009) and transference of a long noncoding RNA (Pan et al., 2017). Still in gastric cancers, the signaling for tumor cell proliferation through MAPK can be mediated by exosomal CD97 (Li C. et al., 2015). In human bladder cancer, induction of cell proliferation was observed when the human bladder cancer cells T24 and 5637 were treated with T24 tumor cell-derived exosomes, in a mechanism also mediated by activation of the Akt and ERK pathways (Yang et al., 2013). In addition, glioblastomaderived exosomes were shown to induce proliferation of the human glioma U87 cell line (Skog et al., 2008) in a mechanism dependent of the CLIC1 protein (Setti et al., 2015). In a narrower context related to prostate cancer treatment, namely the diminished availability of androgens caused by androgendeprivation therapy, prostate cancer LNCaP cells cultured in the presence of androgens secrete exosomes enriched in CD9, which in turn induce the proliferation of androgen-deprived LNCaP cells (Soekmadji et al., 2016). Another example involves the promotion of in vivo growth of murine melanomas by systemic treatment of mice with melanoma-derived exosomes, which a ccelerated growth and inhibited apoptosis of melanoma tumors in vivo (Matsumoto et al., 2017).

In addition to the effects on cell proliferation, tumor-derived exosomes can also modify the migratory status of recipient malignant cells. Nasopharyngeal carcinoma-derived exosomes carrying Epithelial to Mesenchymal transition (EMT)-inducing signals, including TGF- $\beta$, Hypoxia-Inducible Factor 1 alpha (HIF1 $\alpha$ ) (Aga et al., 2014), Matrix Metalloproteinases (MMPs) (You et al., 2015), Notch1, LMP1 Casein Kinase II and Annexin A2 (Yoshizaki et al., 2013; Jeppesen et al., 2014; Kruger et al., 2014; Ung et al., 2014; Cha et al., 2015), were shown to enhance the migratory capacity of the tumor recipient cells. Another example involves exosomes derived from hypoxic prostate cancer cells, which induced increased invasiveness and motility of naïve human prostate cancer cells (Ramteke et al., 2015).

In addition to several works reporting their pro-tumorigenic effects, exosomes were also shown to play a role in tumor-tumor communication by transferring chemoresistance. Since Corcoran and colleagues reported that exosomes can transfer Docetaxel resistance in prostate cancer (Corcoran et al., 2012), similar phenomena have been described in distinct tumor contexts, such as in lung, breast and liver cancers (Takahashi et al., 2014; Xiao et al., 2014; Kong et al., 2015). Indeed, in lung cancer the transfer of Cisplatin resistance is mediated by production of exosomes containing low levels of miRNA miR-100-5p by donor resistant cells, which in turn leads to an increased expression 
of the mammalian target of Rapamycin (mTOR) protein and chemoresistance in the recipient cells (Qin et al., 2017). In breast cancer, miRNA packed in exosomes from drug-resistant cells can modify the expression of specific target genes, including Sprouty2 (targeted by miR-23a), PTEN (targeted by miR-222), APC4 (targeted by miR-452) and p27 (targeted by miR-24), modulating chemoresistance in recipient cells that incorporate these exosomes (Chen et al., 2014a; Mao et al., 2016). In fact, exosomal miR-222 plays a key role in this process (Chen et al., 2014b; Yu et al., 2016), as the silencing of miR-221/222 prevents the transmission of resistance (Wei et al., 2014). Besides miRNAs, the transfer of exosomal mRNAs that encode proteins that confer drug resistance may lead to chemoresistance in the recipient cell. GSTP1 exosomal mRNA from breast cancer cells resistant to Adriamycin, for instance, confer resistance to previously sensitive cells. Importantly, identification of GSTP1 in circulating exosomes from peripheral blood of patients was correlated with worst prognosis in breast cancer patients treated with Adriamycin (Yang et al., 2017).

\section{EXOSOMES IN TUMOR-FIBROBLAST COMMUNICATION}

An ideal metabolic and physiological environment for tumor growth requires a supportive stroma. Fibroblasts are the most abundant cells in the majority of solid tissues, participating in responses to environmental cues and constituting a frequent target of tumor-derived signals (Olumi et al., 1999; Orimo et al., 2005; Hu et al., 2015). Amongst these signals, exosomes produced by tumor cells have been described as important modulators of the activation status of fibroblasts and to play a major role in the setup of tumor microenvironments (Table 1). One of the factors involved in the activation of these cells, frequently named Cancer-Associated Fibroblasts (CAFs), is Transforming Growth Factor beta (TGF- $\beta$ ) (Tomasek et al., 2002), which can be carried to the extracellular milieu by exosomes and induce differentiation of CAFs (Webber et al., 2010, 2015). In addition, prostate cancerderived exosomes containing miR-100, -21 , and -139 , were shown to induce RANKL and Metalloproteinases expression in CAFs, playing a potential role in prostate cancer progression and metastasis (Sanchez et al., 2016). Furthermore, under hypoxic conditions, prostate cancer cells release exosomes containing nearly three times more proteins than those in normoxic conditions, which induce activation of CAFs (Ramteke et al., 2015), and have been associated with the promotion of EMT, stemness, and angiogenesis by prostate cancer cells (Giannoni et al., 2010; Fiaschi et al., 2013). Tumor-derived exosomes were also described as regulators of metabolism in the tumor microenvironment, as breast cancer tumors could suppress glucose uptake by non-tumor cells, including lung fibroblasts, via secretion of exosomes containing miR-122, increasing glucose availability and facilitating metastasis (Fong et al., 2015).

The genetic profile of fibroblasts that take up exosomes also interferes with the effectiveness of the cell-to-cell communication mediated by exosomes. For example, fibroblasts deficient in BRCA1, a tumor suppressor gene with role in DNA repair, internalize bigger amounts of serum-derived exosomes when compared to wild type counterparts (Hamam et al., 2016). In addition, these cells were shown to suffer malignant transformation when exposed to sera-derived exosomes from oncologic patients. It suggests that oncosuppressor genes can prevent integration of exosome information (including those from tumor cells) and protect these cells from pro-tumorigenic messages (Abdouh et al., 2017).

It has also been shown that tumor-derived exosomal effects in fibroblasts is also influenced by the aggressiveness of carcinoma cells. For example, when internalized by stromal fibroblasts, mammary carcinoma-derived exosomes carrying the Neuroblast Differentiation-associated protein AHNAK induce phenotype shifting of CAF, which is frequently associated with cancer progression. Notably, the expression of AHNAK varies according to the aggressiveness of the tumor, being low in benign epithelial breast cells, intermediate in localized malignant cells and high in metastatic cells (Silva et al., 2016).

Tumor-Fibroblast communication mediated by exosomes is not limited to local tissues, as it has also been described at distant tumor-associated microenvironments, such as pre-metastatic niches. For example, once internalized by fibroblasts, breast, and colorectal cancers and leukemia cells-derived exosomes containing the transcript of the enzyme Telomerase hTERT mRNA contributed to the establishment of pre-metastatic niches by increasing fibroblast proliferation and lifespan (Gutkin et al., 2016). In the context of malignant-ascites, gastric and ovarian tumor-derived exosomes may participate in the transformation of normal mesothelial cells into CAF by Mesothelial-Mesenchymal transition. Also, the augmented expression of CAF markers, such as Fibroblast Activation Protein, $\alpha$-SMA and Fibronectin, can induce TGF- $\beta 1$ expression, increasing peritoneum fibrosis and preparing this site for metastasis (Wei et al., 2017). Similar fibrotic effects have been found in exosomal CD151 and Tetraspanin 8 (Tspan8), which are essential components in the crosstalk between cancer initiating cells and their respective tumor-associated cells by, for instance, contributing to ECM remodeling (Yue et al., 2015). In addition, exosomes derived from lung-tropic tumors, such as some types of breast cancers, express high levels of Integrins $\alpha 6 \beta 1$ and/or $\alpha 6 \beta 4$, which allow them to specifically bind to lung fibroblasts, induce upregulation of S100A4, A6, A10, A11, A13, and A16, and lead to the formation of lung-pre-metastatic niches supportive of metastasis (Hoshino et al., 2015).

The crosstalk between stromal and tumor cells is bidirectional, and hence CAF-derived exosomes may act in tumor cells as well as in other non-tumor cells of the tumor microenvironment (Table 1). In esophageal cancer, for instance, it was shown that CAF-derived exosomes containing several microRNA species, including miR-33a, miR-326, play a role in tumor progression, influencing tumor cell adhesion, endocytosis, and cell-cell junctions (Nouraee et al., 2016). Furthermore, pancreatic CAFs, cells intrinsically resistant to the chemotherapeutic agent Gemcitabine, secrete chemoresistanceinducing exosomes when grown in the presence of this drug. This process, mediated by exosomal miR-146a and Snail, has been shown to mediate transfer of resistance to chemosensitive L3.6 
TABLE 1 | Exosomal-mediated phenotypes associate with cancer progression.

\begin{tabular}{|c|c|c|c|}
\hline Process & Exosomal factor & Effect & References \\
\hline \multicolumn{4}{|c|}{ TUMOR-DERIVED EXOSOMAL FACTORS } \\
\hline \multirow{4}{*}{$\begin{array}{l}\text { Cancer progression } \\
\text { and metastasis }\end{array}$} & TGF- $\beta$ & Differentiation of fibroblast into CAF & Webber et al., 2010, 2015 \\
\hline & $\operatorname{miR}-100,-21,-139$ & ECM remodeling and modulation of cell migration & Sanchez et al., 2016 \\
\hline & $\begin{array}{l}\text { TGF- } \beta 2 \text {, TNF } 1 \alpha, \text { IL-6, TSG101, Akt, ILK1, } \\
\beta \text {-Catenin }\end{array}$ & $\begin{array}{l}\text { Activation of prostate CAF by promotion of EMT, } \\
\text { stemness and angiogenesis }\end{array}$ & $\begin{array}{l}\text { Giannoni et al., 2010; Fiaschi } \\
\text { et al., 2013; Ramteke et al., } 2015\end{array}$ \\
\hline & $\begin{array}{l}\text { Neuroblast Differenciation-Associated protein } \\
\text { (AHNAK) }\end{array}$ & Differentiation of fibroblast into CAF & Silva et al., 2016 \\
\hline Metabolic Environment & miR-122 & Suppression of glucose uptake & Fong et al., 2015 \\
\hline \multirow{3}{*}{$\begin{array}{l}\text { Establishment of } \\
\text { Pre-metastatic niches }\end{array}$} & hTERT mRNA & Increased fibroblast proliferation and lifespan & Gutkin et al., 2016 \\
\hline & CD151, Tetraspanin 8 & Fibrosis and ECM remodeling & Yue et al., 2015 \\
\hline & Integrin $\alpha 6 \beta 1, \alpha 6 \beta 4$ & $\begin{array}{l}\text { Lung-pre-metastatic niche formation mediated by } \\
\text { S100A4, A6, A10, A11, A13, and A16 }\end{array}$ & Hoshino et al., 2015 \\
\hline \multicolumn{4}{|c|}{ FIBROBLAST-DERIVED EXOSOMAL FACTORS } \\
\hline \multirow{4}{*}{$\begin{array}{l}\text { Cancer progression } \\
\text { and/or metastasis }\end{array}$} & EphA2 & Induction of proliferation & Takasugi et al., 2017 \\
\hline & Wnt10b & Induction of breast cancer metastasis to liver & Chen et al., 2017 \\
\hline & $\mathrm{miR}-21,-278 \mathrm{e}$, and -143 & Activation of EMT in breast cancer & Donnarumma et al., 2017 \\
\hline & $\operatorname{miR}-33 a,-326$ & $\begin{array}{l}\text { Influence in tumor cell adhesion, endocytosis and } \\
\text { cell-cell junction }\end{array}$ & Nouraee et al., 2016 \\
\hline \multirow[t]{2}{*}{ Metabolic Switch } & $\begin{array}{l}\operatorname{miRNA}-302 d,-29 b,-22,-155,-25 \\
-29 a,-23 a,-21,-16,-222,-24,-199 a \\
-125 b,-144\end{array}$ & $\begin{array}{l}\text { Down-regulation of genes related to OXPHOS by } \\
\text { CAF exosomes }\end{array}$ & Zhao et al., 2016 \\
\hline & $\begin{array}{l}\text { Lactate, Acetate, Citrate, Pyruvate, } \\
\alpha \text {-Ketoglutarate, Fumarate, Malate, } \\
\text { aminoacids such as Gln, Arg, Glu, Pro, Ala, } \\
\text { Thr, Ser, Asn, Val, Leu, Phe, lle, Gly, or lipids } \\
\text { such as Stearate and Palmitate }\end{array}$ & $\begin{array}{l}\text { Modulation of glycolysis, tricarboxylic acid cycle, } \\
\text { lipid and protein synthesis by CAF exosomes }\end{array}$ & Zhao et al., 2016 \\
\hline Chemoresistance & miR-146a, Snail & Induction of CAF chemoresistance & 2017 \\
\hline
\end{tabular}

and chemoresistant PANC1 and AsPC1 pancreatic cancer cells (Richards et al., 2017). Moreover, it was shown that inhibition of exosomes secretion by CAF prevented chemoresistance in cases of colorectal carcinoma (Hu et al., 2015). The growth of cancer cells can also be influenced by the altered secretome of senescent cells. In fact, exosomes from senescent fibroblasts induce proliferation of MCF-7 human breast cancer cells, in a mechanism mediated by EphA2 (Takasugi et al., 2017). CAFderived exosomes are also capable to support tumor growth by providing nutrients to malignant cells. In fact, by modulating mitochondrial oxidative phosphorylation and glycolysis, CAFderived exosomes can contain complete metabolites that may be used under nutrient deprivation stress conditions by tumor cells (Zhao et al., 2016).

Another important mediator in CAF differentiation and tumor biology is P85- $\alpha$, as the downregulation of this factor promotes not only cancer progression via EMT by the Wnt10b paracrine pathway, but also metastatic progression. In addition, P85- $\alpha$ downregulation in fibroblasts is associated to Wnt10b upregulation in fibroblast-derived exosomes, which in turn induce breast cancer metastatic progression to liver (Chen et al., 2017). EMT is also modulated by CAF-derived exosomes containing miRs-21, $-278 \mathrm{e}$, and-143, influencing breast cancer cell phenotype and aggressiveness (Donnarumma et al., 2017). Taking advantage of this communication route involving modulation of tumor biology by fibroblast-derived exosomes, Kamerkar et al. showed that normal fibroblast-like mesenchymal cells can be engineered to carry interfering RNA or Short Hairpin RNA. Specifically, it was shown that engineered cells can produce exosomes capable to preferentially bind to tumor cells, target oncogenic KRAS and suppress cancer in multiple mouse models of pancreatic cancer (Kamerkar et al., 2017).

\section{EXOSOMES IN TUMOR-ENDOTHELIAL CELLS COMMUNICATION}

Endothelial cells (ECs) are key components of the tumor microenvironment not only by providing a conduit to nutrients, but also by representing a source of trophic factors. In this 
context, exosomes also play an instrumental role in tumorEC communication (Table 2). For instance, the process of neovascularization was shown to be modulated by Myeloid leukemia-derived exosomes enriched in Vascular Cell Adhesion Molecule (VCAM)-1 and Intercellular Adhesion Molecule (ICAM)-1 (Taverna et al., 2012). In addition, increased vascularization has been associated with packaging of miR92a in leukemia-derived exosomes (Umezu et al., 2013) and of CO-029/D6.1A Tetraspanin in pancreatic cancer-derived exosomes (Gesierich et al., 2006). It was also demonstrated that upregulation of Heparanase in tumor cells, including myeloma and breast cancers, is associated with increased exosomes production and exosomal packaging of Syndecan-1, Vascular Endothelial Growth Factor (VEGF) and Hepatocyte Growth Factor, which lead to increased endothelial invasion through the ECM (Thompson et al., 2013). Additionally, skin cancer-derived exosomes can promote angiogenesis by delivering Epidermal Growth Factor receptor (EGFR) (Al-Nedawi et al., 2009) and miR-9 to ECs (Gajos-Michniewicz et al., 2014). Furthermore, melanoma-derived exosomes were shown to condition sentinel lymph nodes prior to the installation of melanoma cells and further metastasis through upregulation of Collagen 18 and Laminin 5, and production of angiogenic growth factors (Hood et al., 2011).

Tumor-derived exosomes are also known to influence the integrity of vascular barriers, which is frequently associated with metastatic dissemination. Melanoma-derived exosomes, for instance, induce pulmonary vascular leakiness (Peinado et al., 2012) and upregulate genes related to tumor cell recruitment, such as Stabilin 1, Vitronectin, Integrins, and Ephrin receptor $\beta 4$, in lymph nodes (Hood et al., 2011), creating pre-metastatic niches supportive of metastasis. In addition, breast cancer-derived exosomes enriched in miR-105 targets ECs tight junctions by modifying the expression of Claudin 5, Zonula Occludens protein 1, and Occludin, promoting metastasis by destroying vascular endothelial barriers (Zhou M. et al., 2014). Another example involves brain tumor-derived exosomes containing miR-181c, which modulates ECs actin dynamics and promote breakdown of the blood-brain barrier by 3 -Phosphoinostide-dependent Protein Kinase-1 degradation (Tominaga et al., 2015). Similarly, exosomes produced by glioblastoma cells containing high levels of VEGF-A induce ECs permeability and angiogenesis in vitro (Treps et al., 2017).

Hypoxia is another important factor in modulating tumor-EC communication. For example, hypoxic glioblastoma cells release exosomes that interact with ECs, stimulating proliferation and angiogenesis in vitro and in vivo (Skog et al., 2008; Kucharzewska et al., 2013), and also triggering Tissue Factor/Factor VIIadependent activation of hypoxic ECs (Milia et al., 2002; Svensson et al., 2011). Moreover, hypoxic colorectal cancer cells secrete Wnt4-enriched exosomes that promote Beta-Catenin nuclear translocation and proliferation of ECs (Huang and Feng, 2017), while hypoxic breast cancer and hepatocellular carcinoma cells were shown to release pro-angiogenic exosomes enriched in miR-210 (King et al., 2012) and miR-23a (Sruthi et al., 2017), respectively. In addition, exosomes produced by the human squamous carcinoma cell lineage A431 under hypoxic or reoxygenation conditions were shown to modulate the tumor microenvironment by facilitating angiogenesis, and as consequence, metastasis (Park et al., 2010).

\section{EXOSOMES IN TUMOR-LEUKOCYTES COMMUNICATION}

One of the hallmarks of cancer is the ability of tumor cells to employ different strategies to evade the host immune surveillance (Hanahan and Weinberg, 2011). Contemporary evidence points toward a central role of tumor-derived exosomes in modulating the immune response and influencing cancer development by mediating the dialogue between immune and cancer cells (Czernek and Düchler, 2016). In fact, tumor-derived exosomes have been shown to hijack the immune surveillance program of the host by amplifying tumor-derived signals, including those involved in inflammation, and in certain cases, tumorigenesis (Grivennikov et al., 2010; Cavallo et al., 2011) and escape of

TABLE 2 | Effect of tumor-derived exosomes in endothelial cell (EC) biology.

\begin{tabular}{|c|c|c|c|}
\hline Process & Exosomal factor & Effect & References \\
\hline \multirow[t]{4}{*}{ Angiogenesis } & miR-92a and CO-029/D6.1A Tetraspanin & EC tube formation & Gesierich et al., 2006; Umezu et al., 2013 \\
\hline & $\begin{array}{l}\text { Syndecan-1, Vascular Endothelial Growth Factor } \\
\text { (VEGF), Hepatocyte Growth Factor }\end{array}$ & EC invasion & Thompson et al., 2013 \\
\hline & $\begin{array}{l}\text { Epidermal Growth Factor Receptor (EGFR) and } \\
\text { miR-9 }\end{array}$ & Angiogenesis & $\begin{array}{l}\text { Al-Nedawi et al., 2009; Gajos-Michniewicz } \\
\text { et al., } 2014\end{array}$ \\
\hline & $\begin{array}{l}\text { MMP9, Pentraxin 3, IL-8, PDGF-AB/AA, CD26, } \\
\text { Plasminogen Activator Inhibitor 1, Caveolin 1, } \\
\text { Tissue Factor, Factor VIla, Wnt4, miR-210, miR-23a }\end{array}$ & ECs proliferation and angiogenesis & $\begin{array}{l}\text { Svensson et al., 2011; King et al., 2012; } \\
\text { Kucharzewska et al., 2013; Huang and } \\
\text { Feng, 2017; Sruthi et al., } 2017\end{array}$ \\
\hline \multirow[t]{3}{*}{$\begin{array}{l}\text { Integrity of } \\
\text { vascular barriers }\end{array}$} & miR-105 & $\begin{array}{l}\text { Destruction of endothelial barriers and } \\
\text { promotion of metastasis }\end{array}$ & Zhou W. et al., 2014 \\
\hline & $\mathrm{miR}-181 \mathrm{c}$ & Breakdown of blood-brain barrier & Tominaga et al., 2015 \\
\hline & VEGF-A & $\begin{array}{l}\text { Increase in ECs permeability and } \\
\text { angiogenesis }\end{array}$ & Treps et al., 2017 \\
\hline
\end{tabular}


tumor cells from the immune system (Wieckowski et al., 2009; Whiteside, 2013).

It is also known that tumor-derived exosomes are not only key players in the immune editing of the primary tumor niche, but also in the pre-metastatic and metastatic niches, as they can outsmart stromal and immune players into overcoming the immune response (Hanahan and Weinberg, 2011), fostering the setup of pro-metastatic microenvironments (Syn et al., 2016). In this section, we will dissect how exosomes can mediate cellcell communication between the cellular components of the immune system and tumor cells and play a role in tumor biology (Figure 2).

\section{Exosomes Roles in Macrophages and Neutrophils Polarization}

All types of immune cells are potentially sensitive to tumorderived exosomes immunomodulation effects. However, exosomes can induce different levels of modification in each of these cells, as it is the case with macrophages. Activated macrophages, for instance, display a remarkable phenotypic plasticity according to environmental cues, being usually divided into a continuum of $\mathrm{M} 1$ and $\mathrm{M} 2$ functionally polarized states. In general, based on Th1/Th2 polarization,
M1 macrophages are pro-inflammatory and tumoricidal (classically activated), while M2 are anti-inflammatory and tumor supportive (alternatively activated) (Martinez et al., 2008; Gautier et al., 2012; Xue et al., 2014; You et al., 2015). In a tumor microenvironment, macrophages can be educated into Tumor-Associated Macrophages (TAMs) displaying M2 characteristics, promoting angiogenesis and releasing pro-tumorigenic growth factors, chemokines and cytokines (Mantovani et al., 2004; Rogers and Holen, 2011; Quatromoni and Eruslanov, 2012; Schiavoni et al., 2013). In this setting, tumor-derived exosomes have been shown to play a key role in the polarization status of macrophages. For instance, colorectal cancer-derived exosomes induce pro-tumorigenic macrophage phenotypes by using cytoskeleton centric proteins as functional units. In fact, cytoskeleton rearrangement is a primordial characteristic of macrophage activation and maturation (Chen Z. et al., 2016). Another example involves epithelial ovarian cancer, where exosomes containing miR222-3p induced a shift in the activation status of macrophages into a M2 polarization, in a process mediated by down-regulation of the SOCS3/STAT3 pathway (Ying et al., 2016). Furthermore, miR-25-3p- and miR-92a-3p-rich exosomes from human liposarcoma cell lines were observed to induce IL- 6 secretion by TAMs, leading to

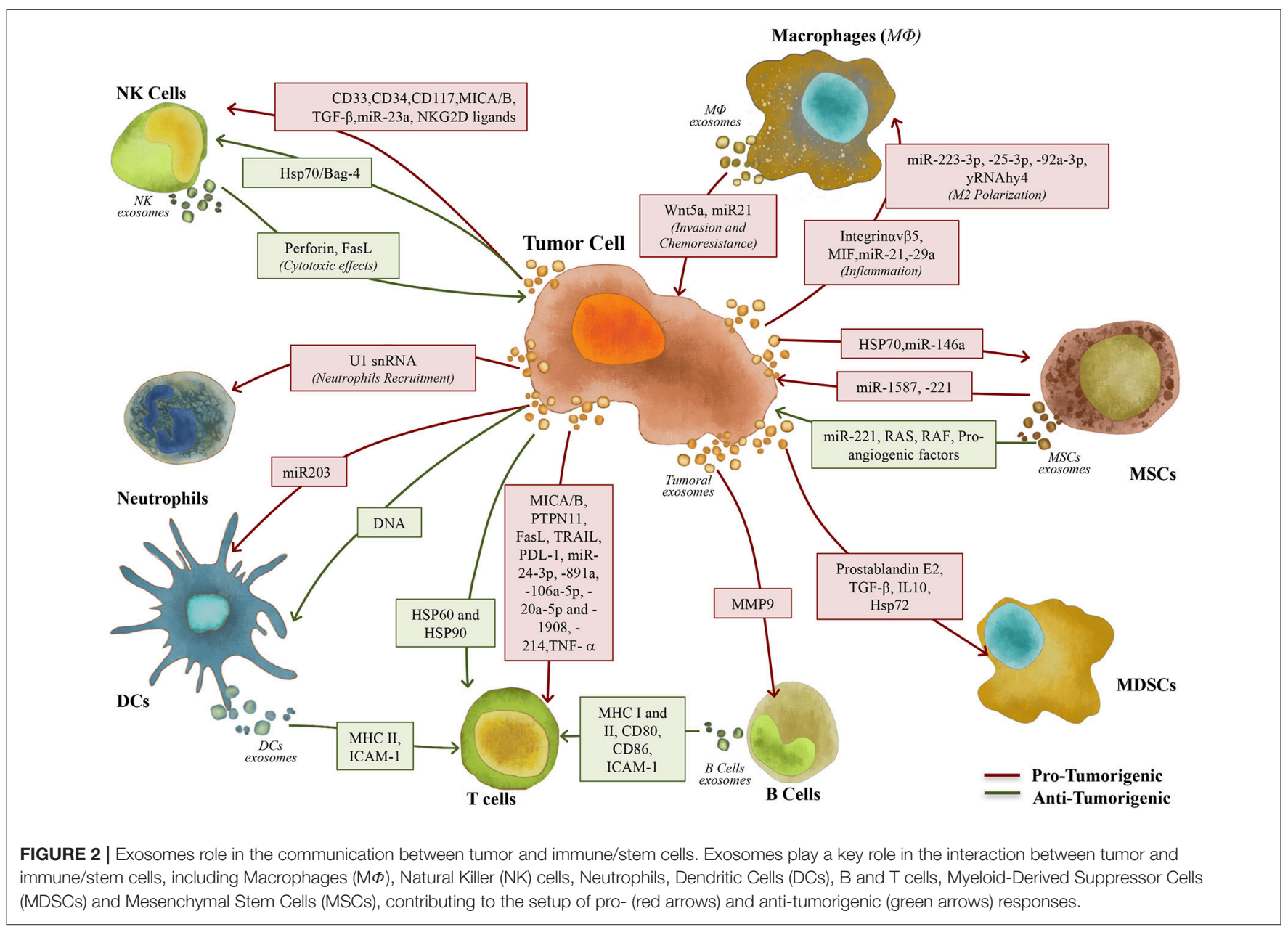


an increase in liposarcoma cellular proliferation (Casadei et al., 2017). In chronic lymphocytic leukemia (CLL), tumor-derived exosomes containing noncoding Y RNA hY4 were shown to induce CLL-associated phenotypes in recipient monocytes, including the release of cytokines, such as $\mathrm{C}-\mathrm{C}$ motif chemokine ligand 2 (CCL2), CCL4, and IL-6, and the expression of PD-L1, suggesting a potential exosome-based mechanism of immune escape (Haderk et al., 2017). In addition to modulate macrophage polarization, tumor-derived exosomes were shown to influence macrophages migration. For example, Bandari et al. showed in a recent report that when exposed to commonly utilized antitumor agents, such as Bortezomib, Carfilzomib, or Melphalan, myeloma cells produce Heparanase-rich exosomes that induce migration and TNF- $\alpha$ secretion by macrophages (Bandari et al., 2018).

Tumor-derived exosomes are frequently related to NF- $\kappa$ B activation in macrophages and promotion of pro-tumorigenic microenvironments. For instance, gastric cancer-derived exosomes were shown to induce NF- $\mathrm{B}$ activation in macrophages, leading to an increase in the expression of pro-inflammatory factors such as IL-6 and TNF- $\alpha$, in turn promoting the proliferation of gastric cancer cells (Wu et al., 2016). Similar observations were obtained by Chow et al., who showed that breast cancer-derived exosomes also stimulate the NF- $\kappa \mathrm{B}$ pathway in macrophages, leading to the secretion of the pro-inflammatory cytokines IL- 6 , TNF- $\alpha$, GCSF, and CCL2 (Chow et al., 2014). Another example involves lung tumor-derived exosomes containing miR-21 and miR-29a. These exosomes were shown to bind to Toll-like receptor (TLR)7 and TLR8, leading to NF- $\kappa B$ activation and secretion of the pro-metastatic inflammatory cytokines TNF- $\alpha$ and IL-6. In turn, these cytokines were shown to induce the formation of a pulmonary microenvironment supportive of lung metastatic burden (Fabbri et al., 2012).

TAMs are also known to induce inflammatory responses, playing a key role in the setup of tumor microenvironments supportive of metastasis formation and progression. For example, once taken up by hepatic resident macrophages, in a mechanism mediated by exosomal Integrin $\alpha \mathrm{V} \beta 5$ (Hoshino et al., 2015), pancreatic cancer-derived exosomes containing high levels of Macrophage Migration Inhibitory Factor (MIF) (CostaSilva et al., 2015) were shown to induce upregulation of secreted factors associated with liver fibrosis, such as TGF $\beta$ (CostaSilva et al., 2015), and pro-inflammatory genes involved with metastasis, such as S100A8 and S100P (Lukanidin and Sleeman, 2012; Hoshino et al., 2015). In response to this inflammatory microenvironment, hepatic stellate cells shift into an activated state marked by upregulation of Fibronectin expression. This Fibronectin-rich microenvironment then promotes the accumulation of bone marrow-derived macrophages and the formation of a pre-metastatic microenvironment supportive of liver metastasis (Costa-Silva et al., 2015).

In addition to mediate immune responses, macrophages can also modulate tumor-derived exosomes biodistribution. Subcapsular sinus $\mathrm{CD} 169^{+}$macrophages, for example, form a physical layer that block tumor-derived exosomes' dissemination in spleen and lymph nodes (Saunderson et al., 2014). In agreement with this, high density of $\mathrm{CD} 169^{+}$macrophages in lymph nodes positively correlates with longer overall survival in patients with colorectal carcinoma (Ohnishi et al., 2013). Pucci et al., however, showed that this macrophage barrier can be disrupted by melanoma-derived exosomes, permitting the entrance of these exosomes in the lymph node cortex, where they interact with $\mathrm{B}$ cells and foster tumor progression by inducing autoantibodies production (Pucci et al., 2016).

Tumor-derived exosomes are not the only players in tumormacrophage communication, as macrophages-derived exosomes can also exert effects in tumor cells biology. For instance, macrophages-derived exosomes can induce tumor invasion by transferring Wnt5a from macrophages to cancer cells, leading to the activation of the $\beta$-Catenin-independent Wnt signaling pathway, in a process that defines a new strategy of malignant invasion by breast cancer (Menck et al., 2013). Moreover, TAMderived exosomes were shown to modulate chemoresistance. In fact, Zheng et al. showed that exosomes produced by TAM containing miR-21 could confer Cisplatin resistance to gastric cancer cells, in a process mediated by down-regulation of PTEN (Zheng et al., 2017). Wu and colleagues highlighted the relevant role of exosomes in the tumor microenvironment, unraveling an additional layer of complexity in the tumor-host communication network. In this work, it was shown that TAMderived exosomes could suppress migration of endothelial cells by targeting the miR-146b-5p/ TRAF6/NF-kB/MMP2 pathway. Interestingly, ovarian cancer-derived exosomes were able to revert this inhibitory effect by transferring lncRNAs (Wu et al., 2017).

Neutrophils are also known as key mediators of innate immune response, as they are essential to protect the host against infection and to support tissue repair (Mayadas et al., 2014). Similar to macrophages, neutrophils also display phenotypic plasticity, which is influenced by different tumor-derived signals and that can exert pro- or anti-tumor effects. Indeed, tumors can manipulate neutrophils early in their differentiation process, creating a diverse repertoire of functional polarization states (Fridlender et al., 2009; Coffelt et al., 2016). In this setting, exosomes have been shown as emerging mediators of tumor-neutrophil interactions. For instance, breast cancerderived exosomes can promote tumor growth by inducing bone marrow-derived neutrophils recruitment to tumor sites (Bobrie et al., 2012). Furthermore, neutrophils have emerged as crucial mediators in the pre-metastatic niche development (Wculek and Malanchi, 2015), as breast cancer-derived exosomal RNAs can activate host stromal TLR3, inducing neutrophil recruitment, which is critical for the setup of pre-metastatic niches (Kenific et al., 2016; Liu et al., 2016).

\section{Exosomes' Role in Suppression of Natural Killers' Cytolytic Response}

Natural killer (NK) cells are another important component of the immune system, as these innate lymphoid cells are able to assemble a rapid cytotoxic activity ("ready to kill"), allowing them to control microbial infections and tumor progression in a process regulated by a balance of activating and inhibitory 
signals (Morvan and Lanier, 2015). Different reports state that the cytotoxicity of NK cells is significantly impaired in oncologic settings, in part due to the immune suppressive effect of tumorderived exosomes. This immune suppressive effect has been associated with altered expression of NK cell activating surface receptors. For instance, exosomes derived from plasma of acute myelogenous leukemia (AML) patients, containing CD33, CD34, CD117, MICA/MICB, and TGF- $\beta$, were shown to decrease cytotoxic activity of $\mathrm{NK}$ cells, in a process involving Smad phosphorylation and down-regulation of NKG2D receptor in NK cells (Szczepanski et al., 2011; Whiteside, 2013), which was reversible by IL-15 (Szczepanski et al., 2011). Another example involves the work of Berchem et al., who showed that tumorderived exosomes produced by hypoxic cells are qualitatively different from normoxic counterparts. Using various tumor models, they revealed that hypoxic tumor-derived exosomes were able to negatively regulate NK cell functions, in a mechanism also mediated by transfer of TGF- $\beta 1$ and decrease of NKG2D levels in NK cells. The authors also described miR-23a and TGF$\beta$ as an immunosuppressive factor transferred to NK cells that directly targets CD107a expression, leading to a decrease of antitumor responses (Berchem et al., 2016). In fact, in the presence of tumor-derived exosomes, NKG2D is one of the most profoundly affected NK receptors, which have MHC class I-related chain A (MICA) and B (MICB) as crucial ligands for its induction (Mincheva-Nilsson and Baranov, 2014). Accordingly, Groh et al. showed that cancer patients exhibit a decrease of NKG2D surface expression on circulating NK cells in comparison with healthy individuals (Groh et al., 2002). Furthermore, Ashiru et al. demonstrated that the shedding of the most frequently expressed MICA allele in human populations, $\mathrm{MICA}^{*} 008$, in tumorderived exosomes induce down-regulation of NKG2D in NK's cell surface, leading to an impaired cytotoxic function (Ashiru et al., 2010). Moreover, a recent study showed that prostate tumor-derived exosomes with NKG2D ligands selectively induce a dose-dependent downregulation of cell surface NKG2D in both NK cells and CD8+ T cells, leading to impaired cytotoxic function of both immune cell types (Lundholm et al., 2014). Tumor-derived exomes bearing NKG2D ligands (such as MIC$\mathrm{A} / \mathrm{B}$ and ULBP 1 and 2) were also shown to act as decoys, impairing NKG2D-mediated NK-cell cytotoxicity and facilitating the immune evasion of leukemia/lymphoma cells (Hedlund et al., 2011).

An additional mechanism of immune evasion was described by Liu et al., who showed that murine mammary-derived exosomes were able to inhibit IL-2-stimulated NK cells proliferation and block IL-2-mediated activation of NK cells, thus abolishing their cytotoxic response to tumor cells (Liu et al., 2006). In addition, tumor-derived exosomes containing death receptor ligands, such as FasL, on their membrane were also found to induce the apoptosis of NK cells, similarly to what happens with T cells (Andreola et al., 2002; Saito et al., 2013). On the other hand, anticancer drugs have been described to induce chemoresistant hepatocellular carcinoma cells to release exosomes that elicit anti-tumor NK cell responses, in a mechanism mediated by exosomal Heat Shock Proteins (Lv et al., 2012). Similar to other tumor-immune cell-cell communication settings, NK cells have also been shown to influence tumor cells biology though production of exosomes. It was illustrated in a recent work of Zhu et al., showing that NK cells-derived exosomes can induce cytotoxic effects in melanoma cells in vitro, representing a potentially novel antitumor strategy (Zhu et al., 2017).

\section{Exosomes Role in Impairment of Cytotoxic Lymphocytes (CTL) Response and Induction of Immune Tolerance/Immune Regulator Cells}

The centerpiece of antitumor immunity is the effective response of $\mathrm{CD}^{+}$and $\mathrm{CD}^{+} \mathrm{T}$ cells. In this setting, tumor-derived exosomes have been also described as potent mediators of proliferation, activation, and apoptosis of these cells, enabling tumor evasion from immune surveillance. For instance, $\mathrm{T}$ cell death has been shown to be induced by tumor-derived exosomes through both extrinsic and intrinsic apoptotic pathways. In fact, induction of $\mathrm{T}$ cells apoptosis by tumor-derived exosomes occurs through receptor-mediated pathways involving Fas Ligand (FasL), TRAIL, and PDL-1 (Abusamra et al., 2005; Kim et al., 2005; Wieckowski et al., 2009). In addition, Abusamra et al. demonstrated that prostate cancer-derived exosomes expressing FasL trigger T-cell apoptosis in a dose-dependent fashion (Abusamra et al., 2005). In another example, head and neck squamous cell carcinoma-derived exosomes were shown to induce activated $\mathrm{CD}^{+} \mathrm{T}$ cells apoptosis through Caspase 3 cleavage, mitochondrial Cytochrome $\mathrm{C}$ release, loss of mitochondrial membrane potential, DNA fragmentation and early membrane changes, including Annexin $\mathrm{V}$ binding (Czystowska et al., 2011). The PI3K/AKT pathway is also targeted by exosomes in activated $\mathrm{CD}^{+} \mathrm{T}$ cells, as tumor-derived exosomes were shown to cause Akt dephosphorylation in a time-dependent manner, leading to downregulation of the antiapoptotic proteins $\mathrm{Bcl}-2, \mathrm{Bcl}-\mathrm{xL}$, and $\mathrm{Mcl}-1$ and upregulation of the pro-apoptotic protein Bax (Czystowska et al., 2009, 2011). Furthermore, the production of tumor-derived exosomes containing MICA/B and FasL is associated with impairment of the effectives of both innate and adaptive immunity (Abusamra et al., 2005; Lundholm et al., 2014). Therefore, it has been suggested that such exosomes are able to modulate lymphocyte functions by mimicking "activation-induced cell death" (AICD) (Blanchard et al., 2002; Perone et al., 2006; Taylor and Gercel-taylor, 2011). Another example involves melanomaderived exosomes, which were shown to suppress $\mathrm{CD}^{+} \mathrm{T}$ cell proliferation and viability by delivering PTPN11 (protein and mRNA) (Wu et al., 2017). In addition, human nasopharyngeal carcinoma-derived exosomes can inhibit $\mathrm{T}$ cell proliferation and differentiation into Th1 and Th17 cells, promoting regulatory T cell (Treg) generation, decreasing ERK, STAT1, and STAT3 phosphorylation and increasing STAT5 phosphorylation in the recipient $\mathrm{T}$ cells. These tumor-derived exosomes also increased the secretion of the pro-inflammatory cytokines IL-1 $\beta$, IL-6, and IL-10, and decreased the release of IFN $\gamma$, IL-2, and IL17, both in $\mathrm{CD}^{+}$and $\mathrm{CD}^{+} \mathrm{T}$ cells. The content of exosomes from patient sera and nasopharyngeal carcinoma cell lines 
was further explored, showing to be enriched in miR-24-3p, $-891 \mathrm{a},-106 \mathrm{a}-5 \mathrm{p},-20 \mathrm{a}-5 \mathrm{p}$, and-1908. The same work showed that these miRNA clusters downregulate the MARK1 signaling pathway, affecting $\mathrm{T}$ cells proliferation and differentiation (Ye et al., 2014).

Unresponsiveness of $\mathrm{CD}^{+} \mathrm{T}$ cells can also be achieved by damaging the TCR (T-cell receptor) signaling pathway, which mediate TCR-MHC-peptide interactions and T cell activation, in a mechanism involving $\mathrm{CD} 3 \zeta$ chain transfer of activating signals to the nucleus. Soderberg et al. demonstrated that melanomaderived exosomes transfer TNF- $\alpha$ to $\mathrm{CD} 4^{+}$and $\mathrm{CD} 8^{+} \mathrm{T}$ cells, affecting the TCR-CD3 complex, and causing $\mathrm{T}$ cell disruption (Soderberg et al., 2007). In agreement, several studies also reported that tumor-derived exosomes from cancer patients mediate inhibition of $\mathrm{CD} 3 \zeta$ chain expression in T cells, impairing $\mathrm{T}$ cell activation (Taylor et al., 2003; Kim et al., 2005; Taylor and Gercel-taylor, 2011).

Another critical step in the anti-tumor immune response is the $\mathrm{CD}^{+}$and $\mathrm{CD} 8^{+} \mathrm{T}$ cells homing to the primary tumor site (Taylor et al., 2003; Kim et al., 2005; Taylor and Gerceltaylor, 2011). Lee et al. showed that by shedding ICAM1 in the membrane of their exosomes, cancer cells prevent the interaction between lymphocytes and endothelial cells, thus decreasing the recruitment of adaptive immune cells (Lee et al., 2010).

Besides impairment of CTL responses, another mechanism present in tumor cells which promote escape from immune surveillance involves interference in the differentiation process of naïve immune cells toward an immunosuppressive phenotype. For example, tumor-derived exosomes are capable of inducing expansion of $\mathrm{CD}^{+} \mathrm{CD} 25^{+} \mathrm{Foxp}^{+}$Treg cells and their suppressor activity, and to trigger $\mathrm{CD} 8^{+} \mathrm{T}$ cells apoptosis (Wieckowski et al., 2009). Additionally, exosomes produced by various types of human and murine tumors were reported to transfer miR214 to peripheral $\mathrm{CD}^{+}{ }^{-} \mathrm{T}$ cells, stimulating immune evasion by downregulating PTEN and promoting Treg expansion (Yin et al., 2014).

In a recent study, Muller et al. showed that tumorderived exosomes can also induce differential regulation of key immune function-related genes in conventional $\mathrm{CD} 4^{+} \mathrm{T}$, $\mathrm{CD}^{+} \mathrm{T}$, and Treg. In $\mathrm{CD} 4^{+} \mathrm{T}$ cells, for instance, inhibitory genes were upregulated by tumor-derived exosomes, which led into a loss of CD69 on their surface and a functional decline of these cells. On the other hand, exosomes induced CD39 expression and adenosine production in Treg, while downregulating mRNA expression levels of the genes involved in the control of immmunosuppressive pathways (Muller et al., 2016). Collectively, by exploiting diverse mechanisms acting in concert, tumor-derived exosomes contribute to an immunosuppressive environment and peripheral tolerance, which play pivotal role in tumor growth and progression.

\section{Exosomes Role in DCs Differentiation and Maturation}

Dendritic cells (DCs) are versatile meditators of the immune system, forming a remarkable network that shapes innate and adaptive immunity, according to peripheral signals (Merad et al.,
2013). The DCs importance is associated with their function as professional antigen-presenting cells (APCs), since they are able to perform antigen presentation and initiation of primary $\mathrm{T}$ cell response, including those frequently directed against tumor cells (Liu et al., 2017).

The presence of tumor-derived exosomes during the generation of DCs was associated with low expression of costimulatory molecules and production of inhibitory cytokines by these cells, in a process followed by suppression of $\mathrm{T}$ cells proliferation and anti-tumor cytotoxicity (Valenti et al., 2006). In addition, tumor-derived exosomes taken up by immature DCs were shown to inhibit the maturation process of these cells (Yang et al., 2011).

The antigen recognition capacity of DCs can also be modulated by tumor-derived exosomes, which affect the expression of pattern recognition receptors (PRRs) in DCs. Pancreatic cancer-derived exosomes, for instance, can downregulate the expression of TLR4 (via miR-203) in DCs, inducing the production of TNF- $\alpha$ and IL-12 and inhibiting DCs-mediated antitumor responses triggered by TLR4 (Zhou M. et al., 2014). In summary, increasing number of reports have been showing that tumor-derived exosomes can also mediate host immunosuppression by modulating the differentiation, maturation and function of DCs.

\section{Exosomes Role in B Cells}

$B$ cells are important players in the tumor-induced modulation of immune response, being the second most abundant tumorinfiltrating lymphocytes (Yuen et al., 2016). In 1996, Raposo et al. reported for the first time that B-lymphocytes secrete exosomes, and that these particles contain MHC class II able to perform antigen presentation and to induce antigen-specific $\mathrm{CD} 4+\mathrm{T}$ cell responses (Raposo et al., 1996). In addition to the several reports of exosomes production by $\mathrm{B}$ cells, and of the potential roles of these particles in the immune system (Escola et al., 1998; Clayton et al., 2005; Rialland et al., 2006; Buschow et al., 2010), these cells were also reported to be influenced by tumorderived exosomes. In fact, esophageal cancer-derived exosomes containing HSP90 can influence naïve B cells to develop into an immunosupressive regulatory phenotype expressing TGF- $\beta$ (Li Y. et al., 2015). Furthermore, melanoma and lymphoma cells were shown to release exosomes that induce IL-10 production in splenic B cells. In turn, IL-10 promote the generation of regulatory B cells which inhibit $\mathrm{T}$ cell activity (Yang et al., 2012), suggesting a novel mechanism of induction of inhibitory B cells based on exosome-driven pathways.

\section{Exosomes Involvement in the Stimulation of Immunity against Cancer}

Exosomes produced by cancer cells are known to predominantly induce immune suppression and to support tumorigenesis. However, several reports show that these nanoparticles are also capable of stimulating immunity (Reiners et al., 2014; Czernek and Düchler, 2016; Liu et al., 2017; Yoshimura et al., 2017). This dual role of tumor-derived exosomes is mainly due to their ability to express tumor-associated antigens. In addition, exosomes are considered ideal sources of antigens for APCs 
education, especially due to its easy collection from the peripheral circulation by the use non-invasive methods. In fact, early reports showed that antigens in tumor-derived exosomes can be transferred to DCs and induce specific anti-tumor immune responses (Andre et al., 2002; Robbins and Morelli, 2014). For instance, DCs pulsed with hepatocellular carcinoma cell (HCC)derived exosomes led to an increase in IFN $\gamma$ levels and CD8+ $\mathrm{T}$ cells, and in the reduction of IL10 and TGF- $\beta$ levels in HCC-bearing mice (Rao et al., 2016). Another example involves cancer cells treated with anti-tumor agents, which can release DNA-containing exosomes capable of activating DCs though the STING-dependent pathway and reinforce antitumor immunity (Kitai et al., 2017).

Additionally, tumor-derived exosomes can enhance antitumor immunity through transfer of cytokines or heat shock proteins (Liu et al., 2017). In fact, HSP60 and HSP90 are abundant in exosomes derived from heat-shocked mouse B lymphoma cells, being these exosomes associated with increased antitumor immune responses by $\mathrm{T}$ cells (Chen et al., 2006). In line with these findings, tumor-derived HSP70/Bag-4+ exosomes stimulate NK cell activity, inducing granzyme B release and pancreatic cancer cell apoptosis (Gastpar et al., 2005). Based on these anti-tumor effects generated by tumor-derived exosomes, several lines of research have been focusing in developing exosome-based tumor vaccines. Common strategies involve genetic modification of exosomes-producing cells in order to modify exosomes content, including IL2 (Yang et al., 2007) and IL18 (Dai et al., 2008) and improve exosome-driven immunogenicity. In addition, other strategies are based on stimulating the release of exosomes that act on NK cell toxicity by stressing tumor cells with, for instance, anti-cancer drugs ( $\mathrm{Lv}$ et al., 2012).

The ability to induce effective immunity is not limited to tumor-derived exosomes, as immune cells can also release exosomes able to act on the immune system and elicit antitumor responses. DC-derived exosomes, for instance, can act as antigen-presenting particles (Zitvogel et al., 1998) and stimulate antigen-specific cytotoxic T lymphocytes in vivo (Raposo et al., 1996; Zitvogel et al., 1998). In addition, DC-derived exosomes containing ICAM-1 and B cells-derived exosomes containing MHC Class I and II molecules, co-stimulatory molecules (CD80 and CD86) and ICAM-1 were shown to promote antigenpresenting function in recipient immune cells (Clayton et al., 2001; Théry et al., 2001; André et al., 2004; Segura et al., 2005). These exosomes can modulate immune responses either directly, by exposing these molecules, or indirectly, by conveying internal components to surrounding cells. Taken the effects mentioned above, DC-derived exosomes represent an important strategy to suppress tumor growth through novel cell-free vaccination approaches (Tian and Li, 2017).

To date, DC-based cellular immunotherapy has exhibited several limitations, such as fluctuations in the molecular composition of DCs, challenges in defining its composition, low levels of membrane expression of peptide-MHC-II complexes, presence of immunosuppressive cytokines able to convert DCs into tolerogenic state, hindrances to store live DCs and problems regarding stability management over longer periods
(Palucka and Banchereau, 2012; Pitt et al., 2016). When compared to DC-based cellular immunotherapy protocols, DC exosomes-based strategies present significant advantages, as exosomes have better defined molecular composition for each patient, higher levels of peptide-MHC-II complexes and higher stability for storage due to their lipid composition (Pitt et al., 2016; Yoshimura et al., 2017). Although further studies are still necessary, important progress has been made in clinical applications of DC exosomes-based vaccines. Indeed, patients with advanced malignancies, including those with non-small cell lung cancer (Morse et al., 2005; Besse et al., 2016), metastatic melanoma (Escudier et al., 2005) and colorectal cancer (Dai et al., 2008), that were vaccinated with DC-derived exosomes displayed activation of T and NK cell-based immune responses. In addition, two phase I (Escudier et al., 2005; Morse et al., 2005) and one phase II clinical trial (Besse et al., 2016) using DC-derived exosomes have now been completed, showing the feasibility and safety of this approach.

\section{EXOSOMES IN TUMOR-STEM/ PROGENITOR/NON-TRANSFORMED CELL COMMUNICATION}

Besides the well-known effects in differentiated cells, tumor-derived exosomes can also induce pro-tumorigenic microenvironments by mediating tumor-stem/progenitor cell communication. Melanoma-derived exosomes, for instance, "educate" bone marrow-derived cells via the horizontal transference of the oncoprotein MET, which leads to mobilization of vasculogenic and hematopoietic bone marrow progenitor cells to ensure vascular proliferation and immunosuppression at the pre-metastatic niches (Peinado et al., 2012). Tumorstem/progenitor cell communication was also described in scenarios of bone metastasis, as exosomes from the bonemetastatic prostate cancer PC3 cells were shown to modulate both osteoclastogenesis and osteoblast proliferation, influencing the process of bone metastasis. In turn, osteoblast-derived exosomes were shown to promote PC3 prostate cancer cell proliferation (Morhayim et al., 2015).

In addition, tumor-derived exosomes were shown to manipulate the process of myeloid precursor cells differentiation toward myeloid-derived suppressor cells (MDSCs), which are known to contribute to tumor progression by allowing immune evasion (Nagaraj and Gabrilovich, 2007). Exosomes derived from breast carcinomas, for instance, were shown to be taken up by bone marrow cells and to switch the differentiation pathways of these cells toward MDSCs via Prostaglandin E2 and TGF- $\beta$, promoting accumulation of COX2, IL6, VEGF and Arginase1 by MDSCs (Xiang et al., 2009). Similarly, glioma stem cell-derived exosomes were shown to act on MDSCs via IL10 and Arginase 1 upregulation and HLA-DR downregulation in CD14+ monocytic MDSCs, leading to inhibition of $\mathrm{T}$ cell activation (via CD25 and CD69) and decrease of Th1 cytokine production (Domenis et al., 2017). In agreement with these findings, tumor-derived exosomes prevented the process of monocytes maturation by switching differentiation toward altered $\mathrm{CD} 14^{+}$ 
monocytes expressing low or absent levels of HLA-DR, which was shown to suppress $\mathrm{T}$ cell proliferation and cytolytic functions (Valenti et al., 2006; Temme et al., 2010). Additionally, Chalmin et al. showed that HSP72+ exosomes derived from several tumor models can stimulate the suppressive function of MDSCs via Stat3 activation, leading to IL-6 production in a MyD88/TLR2-dependant mechanism (Chalmin et al., 2010). This finding was reinforced by the involvement of MyD88, a molecule involved in the propagation of signals generated by the TLR family and production of IL-6, TNF- $\alpha$, and CCL2, in the recruitment and activity of MDSCs by tumor-derived exosomes (Liu et al., 2010). In another example, Wang and colleagues described that multiple myeloma-derived exosomes can create a pro-tumorigenic microenvironment in the bone marrow by inducing MDSCs expansion and activity, endothelial cell growth via the STAT3/p53 pathway and immunosuppression via upregulation of Nitric Oxide Synthase (Wang et al., 2016). Finally, melanoma-derived exosomes can prevent bone marrow myeloid precursors differentiation into DCs via induction of IL-6, favoring the MDSC phenotype (Valenti et al., 2006).

Cancer-derived exosomes can also elicit changes in mesenchymal stem cells (MSCs), which contribute to promote and sustain pro-tumorigenic inflammatory niches. For instance, $\mathrm{HSP}^{+}$lung tumor-derived exosomes induce activation of NF-kB and secretion of IL-6, IL-8, and MCP1 by MSCs, in a TLR2-mediated signaling, leading MSCs into a more inflammatory and tumor supportive phenotype (Li et al., 2016). In a recent report, De Veirman et al. showed that myelomaderived exosomes can transfer miR-146a to mesenchymal cells, leading to the secretion of several cytokines and chemokines by these recipient cells, including CXCL1, IL6, IL-8, IP-10, MCP-1, and CCL-5, and to the promotion of myeloma cells migration and survival (De Veirman et al., 2016). Another example involves exosomes produced by $\mathrm{KMBC}$ cholangiocarcinoma cells that induce IL-6 upregulation in MSCs, which in turn promotes the proliferation of KMBC cells (Haga et al., 2015). In addition, ovarian and breast cancer-derived exosomes can induce MSCs differentiation into CAFs, resulting in increased metalloproteinase activity and expression of a vast array of factors involved in the remodeling of epithelial adherent junction pathways, thus enhancing tumor cell invasiveness and aggressiveness (Clayton et al., 2007; Cho et al., 2011a,b). Similarly, prostate cancer-derived exosomes can induce a process of tumor mimicry through the expression of epithelial neoplastic and vascular markers by adipose tissue-derived MSC, together with the acquisition of aberrant cytogenetic variations and Mesenchymal-to-Epithelial transition (Abd Elmageed et al., 2014). Moreover, breast cancer-derived exosomes also act on adipose tissue-derived MSCs, inducing the secretion of SDF-1, VEGF, CCL5 and TGF- $\beta$, which was associated with differentiation of these MSCs into tumor-associated myofibroblasts (Cho et al., 2011a).

Like other exosomes-based tumor-stroma interaction circuits, tumor-MSCs communication is also bidirectional. For instance, exosomes released by MSCs can upregulate the expression of VEGF in tumor cells via activation of the ERK1/2 and p83 mitogen-activated protein kinase pathways, increasing ECs proliferation and angiogenesis, therefore supporting tumor growth (Zhu et al., 2012). Another example involves exosomes enriched in miR-1587 produced by glioblastoma-associated MSC, which were shown to increase the proliferation and clonogenicity of tumor-initiating glioma stem-like cells (Figueroa et al., 2017). Interestingly, bone marrow, umbilical cord, and adipose tissue MSC-derived exosomes displayed differential effects on the proliferation of U87MG glioblastoma cells, indicating that the origin of the stem cells might be of relevance toward its pro-tumorigenic effects (Del Fattore et al., 2015). Furthermore, exosomes produced by bone marrow-derived MSC containing high levels of miR-221 induced proliferation, migration, invasion and adhesion of gastric cancer cells. In addition, exosomal expression of miR-221 was also associated with poor prognosis in patients with gastric cancer (Ma et al., 2017).

Another relevant aspect influenced by exosomal tumorstem/progenitor cell communication is chemoresistance. Although chemoresistance frequently originates from selection of resistant tumor cell clones after drug exposure, drug resistance can also rise from the transference of biomolecules produced by stromal cells to exosomes. In pre-clinical models, for example, bone marrow stromal cell-derived exosomes induced tumor migration, proliferation and drug resistance by reducing the expression of apoptosis-related proteins by multiple myeloma cells (Wang et al., 2014). In addition, MSC-derived exosomes were found to induce resistance to 5-Fluouracyl and Cisplatin via activation of the RAS/RAF/MEK/ERK pathway in gastric cancer cells (Ji et al., 2015). And, finally, exosomal RNA produced by stromal cells were shown to activate RIG-I anti-viral signaling in breast cancer cells, leading to the expansion of therapy resistant breast cancer cells in a mechanism involving NOTCH3 induction (Boelens et al., 2014).

Tumor-derived exosomes have also been shown to act in non-transformed differentiated cells counterparts, inducing the expression of malignant features by these recipient cells. For instance, Chen et al. showed that exosomes are able to mediate intercellular communication between neoplastic and normal cells, promoting a pro-inflammatory phenotype in the latter. Specifically, it was shown that exosomes from arsenitetransformed liver cells activate the IL6, IL8/STAT3 pathway, enhancing miR155 expression and inflammatory properties in normal liver cells (Chen C. et al., 2016). Moreover, exosomes derived from the MatLyLu metastatic prostate tumor cells were capable to induce higher levels of proliferation in normal prostate epithelium cells than exosomes from the less aggressive nonmetastatic Dunning G prostate tumor cells (Halin Bergstrom et al., 2016).

\section{SUMMARY}

Exosomes are biological active vesicles and professional carriers of information in intercellular communication. In an oncologic scenario, they play a pivotal role in shaping the tumor microenvironment by affecting tumor growth and proliferation, mediating the crosstalk between tumor and tumor-associated 
cells and molding the host immune response. As emerging components in tumor-host crosstalk, exosomes modulate elementary steps of tumor progression, such as growth, invasion and immunosurveillance. In addition to effects in local tumor microenvironments, exosomes released from tumors were shown to mediate distant cell-cell communication processes which result in the setup of pro-tumorigenic microenvironments supportive of metastatic dissemination. This is achieved, for instance, though modulation of fibroblast activation, ECM production, angiogenesis and immunesurveillance. As both tumor- and stroma-derived exosomes are found abundantly at the peripheral circulation, they represent a precious opportunity to access non-invasively and in real time the biological status of the tumor microenvironment. Taking into account the relevance of non-tumor cells in cancer progression, this may provide a new source of biological markers with application in not only prediction of prognosis, but also in disease follow-up during and after therapeutic intervention. In addition to the current efforts in investigating the application of exosomes as anti-tumor tools (such as DC-derived exosomes), the further comprehension of the basic biology of exosomes, including the identification of exosomal components relevant for tumor progression, may represent an opportunity for novel therapeutic strategies based on the targeting of pro-tumorigenic exosomes-based cell-cell communication. However, in spite of the substantial expansion of the field, especially in the last decade, the roadmap to understand the exosomes communication system with the organism is still far from being fully understood. Besides the need for more information on fundamental issues, such as exosomes biogenesis and the mechanisms of exosomal cargo delivery, further effort

\section{REFERENCES}

Abd Elmageed, Z. Y., Yang, Y., Thomas, R., Ranjan, M., Mondal, D., Moroz, K., et al. (2014). Neoplastic reprogramming of patient-derived adipose stem cells by prostate cancer cell-associated exosomes. Stem Cells 32, 983-997. doi: 10.1002/stem.1619

Abdouh, M., Hamam, D., Gao, Z. H., Arena, V., Arena, M., and Arena, G. O. (2017). Exosomes isolated from cancer patients' sera transfer malignant traits and confer the same phenotype of primary tumors to oncosuppressor-mutated cells. J. Exp. Clin. Cancer Res. 36, 113. doi: 10.1186/s13046-017-0587-0

Abusamra, A. J., Zhong, Z., Zheng, X., Li, M., Ichim, T. E., Chin, J. L., et al. (2005). Tumor exosomes expressing Fas ligand mediate CD8 + T-cell apoptosis. Blood Cells Mol. Dis. 35, 169-173. doi: 10.1016/j.bcmd.2005.07.001

Aga, M., Bentz, G. L., Raffa, S., Torrisi, M. R., Kondo, S., Wakisaka, N., et al. (2014). Exosomal HIF1 $\alpha$ supports invasive potential of nasopharyngeal carcinoma-associated LMP1-positive exosomes. Oncogene 33, 4613-4622. doi: 10.1038/onc.2014.66

Al-Nedawi, K., Meehan, B., Kerbel, R. S., Allison, A. C., and Rak, J. (2009). Endothelial expression of autocrine VEGF upon the uptake of tumor-derived microvesicles containing oncogenic EGFR. Proc. Natl. Acad. Sci. U.S.A. 106, 3794-3799. doi: 10.1073/pnas.0804543106

André, F., Chaput, N., Schartz, N. E. C., Flament, C., Aubert, N., Bernard, J., et al. (2004). Exosomes as potent cell-free peptide-based vaccine. I. Dendritic cell-derived exosomes transfer functional MHC class I/peptide complexes to dendritic cells. J. Immunol. 172, 2126-2136. doi: 10.4049/jimmunol.172.4.2126

Andre, F., Schartz, N. E., Movassagh, M., Flament, C., Pautier, P., Morice, P., et al. (2002). Malignant effusions and immunogenic tumour-derived exosomes. Lancet 360, 295-305. doi: 10.1016/S0140-6736(02)09552-1 is still necessary in the standardization of methods involving exosomes purification and characterization. The establishment of standard methods for exosomes isolation, as well as of a consensus regarding biological and physical characteristics that define a group of extracellular vesicles as exosomes, such as the one proposed by the EV-TRACK Consortium (EV-TRACK Consortium et al., 2017), are essential. This is of great relevance, as the myriad of methods for exosomes isolation described in the literature (such as ultracentrifugation, immuneprecipitation and size exclusion chromatography) has the potential to complicate the reproducibility of current and future works and the overall establishment and progress of this flourishing research field.

\section{AUTHOR CONTRIBUTIONS}

BC-S: organization of content and structure, writing and reviewing; SC: writing exosomes role in tumor-fibroblast and tumor-endothelial cells communication, figures preparation; JM: writing exosomes role in tumor-immune system communication, preparation of figures; NC: writing exosomes role in tumor stem/progenitor cells communication. MS: writing introduction and the role of exosomes in tumor-tumor communication.

\section{ACKNOWLEDGMENTS}

Keren Lópes Fernández and to "Art Keepers" for the preparation of the illustrations. This study was supported by the Champalimaud Foundation and grant 751547 from H2020-MSCA-IF-2016.
Andreola, G., Rivoltini, L., Castelli, C., Huber, V., Perego, P., Deho, P., et al. (2002). Induction of lymphocyte apoptosis by tumor cell secretion of FasL-bearing microvesicles. J. Exp. Med. 195, 1303-1316. doi: 10.1084/jem.20011624

Ashiru, O., Boutet, P., Fernández-Messina, L., Agüera-González, S., Skepper, J. N., Valás-Gómez, M., et al. (2010). Natural killer cell cytotoxicity is suppressed by exposure to the human NKG2D ligand MICA*008 that is shed by tumor cells in exosomes. Cancer Res. 70, 481-489. doi: 10.1158/0008-5472.CAN-09-1688

Bandari, S. K., Purushothaman, A., Ramani, V. C., Brinkley, G. J., Chandrashekar, D. S., Varambally, S., et al. (2018). Chemotherapy induces secretion of exosomes loaded with heparanase that degrades extracellular matrix and impacts tumor and host cell behavior. Matrix Biol. 65, 104-118. doi: 10.1016/j.matbio. 2017.09.001

Becker, A., Thakur, B. K., Weiss, J. M., Kim, H. S., Peinado, H., and Lyden, D. (2016). Extracellular vesicles in cancer: cell-to-cell mediators of metastasis. Cancer Cell 30, 836-848. doi: 10.1016/j.ccell.2016.10.009

Berchem, G., Noman, M. Z., Bosseler, M., Baconnais, S., Le, E., Nanbakhsh, A., et al. (2016). Hypoxic tumor-derived microvesicles negatively regulate NK cell function by a mechanism involving TGF- $\beta$ and miR23a transfer. Oncoimmunology 5, 1-13. doi: 10.1080/2162402X.2015.1062968

Besse, B., Charrier, M. L., Lapierre, V.,r., Dansin, E., Lantz, O., Planchard, D., et al. (2016). Dendritic cell-derived exosomes as maintenance immunotherapy after first line chemotherapy in NSCLC. Oncoimmunology 5:e1071008. doi: 10.1080/2162402X.2015.1071008

Bissell, M. J., and Hines, W. C. (2011). Why don't we get more cancer? A proposed role of the microenvironment in restraining cancer progression. Nat. Med. 17, 320-329. doi: 10.1038/nm.2328

Blanchard, N., Lankar, D., Faure, F., Regnault, A., Dumont, C., Raposo, G., et al. (2002). TCR activation of human $T$ cells induces the production of 
exosomes bearing the TCR/CD3/zeta complex. J. Immunol. 168, 3235-3241. doi: 10.4049/jimmunol.168.7.3235

Bobrie, A., Krumeich, S., Reyal, F., Recchi, C., Moita, L. F., Seabra, M. C., et al. (2012). Rab27a supports exosome-dependent and -independent mechanisms that modify the tumor microenvironment and can promote tumor progression. Cancer Res. 72, 4920-4930. doi: 10.1158/0008-5472.CAN-12-0925

Boelens, M. C., Wu, T. J., Nabet, B. Y., Xu, B., Qiu, Y., Yoon, T., et al. (2014). Exosome transfer from stromal to breast cancer cells regulates therapy resistance pathways. Cell 159, 499-513. doi: 10.1016/j.cell.2014.09.051

Buschow, S. I., van Balkom, B. W., Aalberts, M., Heck, A. J., Wauben, M., and Stoorvogel, W. (2010). MHC class II-associated proteins in B-cell exosomes and potential functional implications for exosome biogenesis. Immunol. Cell Biol. 88, 851-856. doi: 10.1038/icb.2010.64

Casadei, L., Calore, F., Creighton, C. J., Guescini, M., Batte, K., Iwenofu, O. H., et al. (2017). Exosome-derived miR-25-3p and miR-92a-3p stimulate liposarcoma progression. Cancer Res. 77, 3846-3856. doi: 10.1158/0008-5472.CAN-16-2984

Cavallo, F., De Giovanni, C., Nanni, P., Forni, G., and Lollini, P.-L. (2011). 2011: the immune hallmarks of cancer. Cancer Immunol. Immunother. 60, 319-326. doi: 10.1007/s00262-010-0968-0

Cha, D. J., Franklin, J. L., Dou, Y., Liu, Q., Higginbotham, J. N., Demory Beckler, M., et al. (2015). KRAS-dependent sorting of miRNA to exosomes. eLife 4:e07197. doi: 10.7554/eLife.07197

Chalmin, F., Ladoire, S., Mignot, G., Vincent, J., Bruchard, M., Boireau, W., et al. (2010). Membrane-associated Hsp72 from tumor-derived exosomes mediates STAT3-dependent immunosuppressive function of mause and human myeloidderived suppressor cells. J. Clin. Invest. 120, 457-471. doi: 10.1172/JCI40483

Chargaff, E., and West, R. (1946). The biological significance of the thromboplastic protein of blood. J. Biol. Chem. 166, 189-197.

Chen, C., Luo, F., Liu, X., Lu, L., Xu, H., and Yang, Q. (2016). NF-kB-regulated exosomal miR-155 promotes the inflammation associated with arsenite carcinogenesis. Cancer Lett. 388, 21-33. doi: 10.1016/j.canlet.2016.11.027

Chen, W., Wang, J., Shao, C., Liu, S., Yu, Y., Wang, Q., et al. (2006). Efficient induction of antitumor $\mathrm{T}$ cell immunity by exosomes derived from heat-shocked lymphoma cells. Eur. J. Immunol. 36, 1598-1607. doi: 10.1002/eji.200535501

Chen, W. X., Cai, Y. Q., Lv, M. M., Chen, L., Zhong, S. L., Ma, T. F., et al. (2014a). Exosomes from docetaxel-resistant breast cancer cells alter chemosensitivity by delivering microRNAs. Tumour Biol. 35, 9649-9659. doi: 10.1007/s13277-014-2242-0

Chen, W. X., Liu, X. M., Lv, M. M., Chen, L., Zhao, J. H., Zhong, S. L., et al. (2014b). Exosomes from drug-resistant breast cancer cells transmit chemoresistance by a horizontal transfer of microRNAs. PLoS ONE 9:e95240. doi: 10.1371/journal.pone.0095240

Chen, Y., Zeng, C., Zhan, Y., Wang, H., Jiang, X., and Li, W. (2017). Aberrant low expression of $\mathrm{p} 85 \alpha$ in stromal fibroblasts promotes breast cancer cell metastasis through exosome-mediated paracrine Wnt10b. Oncogene 36, 4692-4705. doi: 10.1038/onc.2017.100

Chen, Z., Yang, L., Cui, Y., Zhou, Y., and Yin, X. (2016). Cytoskeleton-centric protein transportation by exosomes transforms tumor-favorable macrophages. Oncotarget 7, 27-34. doi: 10.18632/oncotarget.11794

Cho, J. A., Park, H., Lim, E. H., Kim, K. H., Choi, J. S., Lee, J. H., et al. (2011a). Exosomes from ovarian cancer cells induce adipose tissuederived mesenchymal stem cells to acquire the physical and functional characteristics of tumor-supporting myofibroblasts. Gynecol. Oncol. 123, 379-386. doi: 10.1016/j.ygyno.2011.08.005

Cho, J. A., Park, H., Lim, E. H., and, Lee, K. W. (2011b). Exosomes from breast cancer cells can convert adipose tissue-derived mesenchymal stem cells into myofibroblast-like cells. Int. J. Oncol. 40, 130-138. doi: 10.3892/ijo.2011.1193

Chow, A., Zhou, W., Liu, L., Fong, M. Y., Champer, J., Haute, D. V., et al. (2014). Macrophage immunomodulation by breast cancer-derived exosomes requires Toll-like receptor 2-mediated activation of NF-кB. Sci. Rep. 4:5750. doi: 10.1038/srep05750

Clayton, A., Court, J., Navabi, H., Adams, M., Mason, M. D., Hobot, J. A., et al. (2001). Analysis of antigen presenting cell derived exosomes, based on immuno-magnetic isolation and flow cytometry. J. Immunol. Methods 247, 163-174. doi: 10.1016/S0022-1759(00)00321-5

Clayton, A., Mitchell, J. P., Court, J., Mason, M. D., and Tabi, Z. (2007). Human tumor-derived exosomes selectively impair lymphocyte responses to interleukin-2. Cancer Res. 67, 7458-7466. doi: 10.1158/0008-5472.CAN-06-3456

Clayton, A., Turkes, A., Navabi, H., Mason, M. D., and Tabi, Z. (2005). Induction of heat shock proteins in B-cell exosomes. J. Cell Sci. 118, 3631-3638. doi: $10.1242 /$ jcs.02494

Coffelt, S. B., Wellenstein, M. D., and de Visser, K. E. (2016). Neutrophils in cancer: neutral no more. Nat. Rev. Cancer 16, 431-446. doi: 10.1038/nrc.2016.52

Corcoran, C., Rani, S., O’Brien, K., O’Neill, A., Prencipe, M., Sheikh, R., et al. (2012). Docetaxel-resistance in prostate cancer: evaluating associated phenotypic changes and potential for resistance transfer via exosomes. PLoS ONE 7:e50999. doi: 10.1371/journal.pone.0050999

Costa-Silva, B., Aiello, N. M., Ocean, A. J., Singh, S., Zhang, H., Thakur, B. K., et al. (2015). Pancreatic cancer exosomes initiate pre-metastatic niche formation in the liver. Nat. Cell Biol. 17, 816-826. doi: 10.1038/ncb3169

Czernek, L., and Düchler, M. (2016). Functions of cancer-derived extracellular vesicles in immunosuppression. Arch. Immunol. Ther. Exp. 65, 311-323. doi: 10.1007/s00005-016-0453-3

Czystowska, M., Han, J., Szczepanski, M. J., Szajnik, M., Quadrini, K., Brandwein, H., et al. (2009). IRX-2, a novel immunotherapeutic, protects human $\mathrm{T}$ cells from tumor-induced cell death. Cell Death Differ. 16, 708-718. doi: $10.1038 /$ cdd.2008.197

Czystowska, M., Szczepanski, M. J., Szajnik, M., Quadrini, K., Brandwein, H., Hadden, J. W., et al. (2011). Mechanisms of T-cell protection from death by IRX-2: a new immunotherapeutic. Cancer Immunol. Immunother. 60, 495-506. doi: 10.1007/s00262-010-0951-9

Dai, S., Wei, D., Wu, Z., Zhou, X., Wei, X., Huang, H., et al. (2008). Phase I clinical trial of autologous ascites-derived exosomes combined with GM-CSF for colorectal cancer. Mol. Ther. 16, 782-790. doi: 10.1038/mt.2008.1

Dashevsky, O., Varon, D., and Brill, A. (2009). Platelet-derived microparticles promote invasiveness of prostate cancer cells via upregulation of MMP-2 production. Int. J. Cancer 124, 1773-1777. doi: 10.1002/ijc.24016

Del Fattore, A., Luciano, R., Saracino, R., Battafarano, G., Rizzo, C., Pascucci, L., et al. (2015). Differential effects of extracellular vesicles secreted by mesenchymal stem cells from different sources on glioblastoma cells. Expert Opin. Biol. Ther. 15, 495-504. doi: 10.1517/14712598.2015.997706

De Veirman, K., Wang, J., Xu, S., Leleu, X., Himpe, E., Maes, K., et al. (2016). Induction of miR-146a by multiple myeloma cells in mesenchymal stromal cells stimulates their pro-tumoral activity. Cancer Lett. 377, 17-24. doi: 10.1016/j.canlet.2016.04.024

Domenis, R., Cesselli, D., Toffoletto, B., Bourkoula, E., Caponnetto, F., Manini, I., et al. (2017). Systemic T Cells immunosuppression of glioma stem cell-derived exosomes is mediated by monocytic myeloid-derived suppressor cells. PLoS ONE 12:e0169932. doi: 10.1371/journal.pone.0169932

Donnarumma, E., Fiore, D., Nappa, M., Roscigno, G., Adamo, A., Iaboni, M., et al. (2017). Cancer-associated fibroblasts release exosomal microRNAs that dictate an aggressive phenotype in breast cancer. Oncotarget 8, 19592-19608. doi: 10.18632/oncotarget.14752

Dvorak, H. F., Quay, S. C., Orenstein, N. S., Dvorak, A. M., Hahn, P., Bitzer, A. M., et al. (1981). Tumor shedding and coagulation. Science 212, 923-924. doi: 10.1126/science.7195067

Dvorak, H. F., Van DeWater, L., Bitzer, A. M., Dvorak, A. M., Anderson, D., Harvey, V. S., et al. (1983). Procoagulant activity associated with plasma membrane vesicles shed by cultured tumor cells. Cancer Res. 43, 4434-4442.

Escola, J. M., Kleijmeer, M. J., Stoorvogel, W., Griffith, J. M., Yoshie, O., and Geuze, H. J. (1998). Selective enrichment of tetraspan proteins on the internal vesicles of multivesicular endosomes and on exosomes secreted by human B-lymphocytes. J. Biol. Chem. 273, 20121-20127. doi: 10.1074/jbc.273.32. 20121

Escudier, B., Dorval, T., Chaput, N., Andr,é, F., Caby, M.-P., Novault, S., et al. (2005). Vaccination of metastatic melanoma patients with autologous dendritic cell (DC) derived-exosomes: results of thefirst phase I clinical trial. J. Transl. Med. 3:10. doi: 10.1186/1479-5876-3-10

EV-TRACK Consortium, Van Deun, J., Mestdagh, P., Agostinis, P., Akay, O., Anand, S., et al. (2017). EV-TRACK: transparent reporting and centralizing knowledge in extracellular vesicle research. Nat. Methods 14, 228-232. doi: $10.1038 /$ nmeth.4185

Fabbri, M., Paone, A., Calore, F., Galli, R., Gaudio, E., and Santhanam, R. (2012). MicroRNAs bind to Toll-like receptors to induce prometastatic in 
fl ammatory response. Proc. Natl. Acad. Sci. U.S.A. 109, E2110-E2116. doi: 10.1073/pnas.1209414109

Falanga, A., Marchetti, M., Vignoli, A., and Balducci, D. (2003). Clotting mechanisms and cancer: implications in thrombus formation and tumor progression. Clin. Adv. Hematol. Oncol. 1, 673-678.

Fiaschi, T., Giannoni, E., Taddei, M. L., Cirri, P., Marini, A., Pintus, G., et al. (2013). Carbonic anhydrase IX from cancer-associated fibroblasts drives epithelialmesenchymal transition in prostate carcinoma cells. Cell Cycle 12, 1791-1801. doi: 10.4161/cc.24902

Figueroa, J., Phillips, L. M., Shahar, T., Hossain, A., Gumin, J., Kim, H., et al. (2017). Exosomes from glioma-associated mesenchymal stem cells increase the tumorigenicity of glioma stem-like cells via transfer of miR-1587. Cancer Res. 77, 5808-5819. doi: 10.1158/0008-5472.CAN-16-2524

Fong, M. Y., Zhou, W., Liu, L., Alontaga, A. Y., Chandra, M., Ashby, J., et al. (2015). Breast-cancer-secreted miR-122 reprograms glucose metabolism in premetastatic niche to promote metastasis. Nat. Cell Biol. 17, 183-194. doi: $10.1038 /$ ncb3094

Fridlender, Z. G., Sun, J., Kim, S., Kapoor, V., Cheng, G., Ling, L., et al. (2009). Polarization of tumor-associated neutrophil phenotype by TGF-beta: "N1" versus “N2" TAN. Cancer Cell 16, 183-194. doi: 10.1016/j.ccr.2009.06.017

Fu, H., Yang, H., Zhang, X., and Xu, W. (2016). The emerging roles of exosomes in tumor-stroma interaction. J. Cancer Res. Clin. Oncol. 142, 1897-1907. doi: 10.1007/s00432-016-2145-0

Gajos-Michniewicz, A., Duechler, M., and Czyz, M. (2014). MiRNA in melanomaderived exosomes. Cancer Lett. 347, 29-37. doi: 10.1016/j.canlet.2014.02.004

Gastpar, R., Gehrmann, M., Bausero, M. A., Asea, A., Gross, C., Schroeder, J. A., et al. (2005). Heat shock protein 70 surface-positive tumor exosomes stimulate migratory and cytolytic activity of natural killer cells. Cancer Res. 65, 5238-5247. doi: 10.1158/0008-5472.CAN-04-3804

Gautier, E. L., Shay, T., Miller, J., Greter, M., Jakubzick, C., Ivanov, S., et al. (2012). Gene-expression profiles and transcriptional regulatory pathways that underlie the identity and diversity of mouse tissue macrophages. Nat. Immunol. 13, 1118-1128. doi: 10.1038/ni.2419

Gesierich, S., Berezovskiy, I., Ryschich, E., and Zoller, M. (2006). Systemic induction of the angiogenesis switch by the tetraspanin D6.1A/CO-029. Cancer Res. 66, 7083-7094. doi: 10.1158/0008-5472.CAN-06-0391

Giannoni, E., Bianchini, F., Masieri, L., Serni, S., Torre, E., Calorini, L., et al. (2010). Reciprocal activation of prostate cancer cells and cancer-associated fibroblasts stimulates epithelial-mesenchymal transition and cancer stemness. Cancer Res. 70, 6945-6956. doi: 10.1158/0008-5472.CAN-10-0785

Grivennikov, S. I., Greten, F. R., and Karin, M. (2010). Immunity, inflammation, and cancer. Cell 140, 883-899. doi: 10.1016/j.cell.2010.01.025

Groh, V., Wu, J., Yee, C., and Spies, T. (2002). Tumour-derived soluble MIC ligands impair expression of NKG2D and T-cell activation. Nature 419, 734-738. doi: 10.1038/nature01112

Gutkin, A., Uziel, O., Beery, E., Nordenberg, J., Pinchasi, M., Goldvaser, H., et al. (2016). Tumor cells derived exosomes contain hTERT mRNA and transform nonmalignant fibroblasts into telomerase positive cells. Oncotarget 7, 59173-59188. doi: 10.18632/oncotarget.10384

Haderk, F., Schulz, R., Iskar, M., Cid, L. L., Worst, T., Willmund, K. V., et al. (2017). Tumor-derived exosomes modulate PD-L1 expression in monocytes. Sci. Immunol. 2:eaah5509. doi: 10.1126/sciimmunol.aah5509

Haga, H., Yan, I. K., Takahashi, K., Wood, J., Zubair, A., and Patel, T. (2015). Tumour cell-derived extracellular vesicles interact with mesenchymal stem cells to modulate the microenvironment and enhance cholangiocarcinoma growth. J. Extracell. Vesicles 4:24900. doi: 10.3402/jev.v4.24900

Halin Bergström, S., Hägglöf, C., Thysell, E., Bergh, A., Wikström, P., and Lundholm, M. (2016). Extracellular vesicles from metastatic rat prostate tumors prime the normal prostate tissue to facilitate tumor growth. Sci. Rep. 6:31805. doi: $10.1038 /$ srep31805

Hamam, D., Abdouh, M., Gao, Z. H., Arena, V., Arena, M., and Arena, G. O. (2016). Transfer of malignant trait to BRCA1 deficient human fibroblasts following exposure to serum of cancer patients. J. Exp. Clin. Cancer Res. 35:80. doi: 10.1186/s13046-016-0360-9

Hanahan, D., and Weinberg, R. A. (2011). Hallmarks of cancer: the next generation. Cell 144, 646-674. doi: 10.1016/j.cell.2011.02.013

Hedlund, M., Nagaeva, O., Kargl, D., Baranov, V., and Mincheva-Nilsson, L. (2011). Thermal- and oxidative stress causes enhanced release of NKG2D ligand-bearing immunosuppressive exosomes in leukemia/lymphoma, T., and B cells. PLoS ONE 6:e16899. doi: 10.1371/journal.pone.0016899

Helley, D., Banu, E., Bouziane, A., Banu, A., Scotte, F., Fischer, A. M., et al. (2009). Platelet microparticles: a potential predictive factor of survival in hormonerefractory prostate cancer patients treated with docetaxel-based chemotherapy. Eur. Urol. 56, 479-484. doi: 10.1016/j.eururo.2008.06.038

Hood, J. L., San, R. S., and Wickline, S. A. (2011). Exosomes released by melanoma cells prepare sentinel lymph nodes for tumor metastasis. Cancer Res. 71, 3792-3801. doi: 10.1158/0008-5472.CAN-10-4455

Hoshino, A., Costa-Silva, B., Shen, T. L., Rodrigues, G., Hashimoto, A., Tesic Mark, M., et al. (2015). Tumour exosome integrins determine organotropic metastasis. Nature 527, 329-335. doi: 10.1038/nature15756

Hougie, C. (1955). The activation of platelets by plasma. Br. J. Haematol. 1, 213-222. doi: 10.1111/j.1365-2141.1955.tb05502.x

Hu, Y., Yan, C., Mu, L., Huang, K., Li, X., Tao, D., et al. (2015). Fibroblast-derived exosomes contribute to chemoresistance through priming cancer stem cells in colorectal cancer. PLoS ONE 10:e0125625. doi: 10.1371/journal.pone.0125625

Huang, Z., and Feng, Y. (2017). Exosomes derived from hypoxic colorectal cancer cells promote angiogenesis through Wnt4-induced beta-catenin signaling in endothelial cells. Oncol. Res. 25, 651-661. doi: 10.3727/096504016X14752792816791

Italiano, J. E. Jr., Mairuhu, A. T., and Flaumenhaft, R. (2010). Clinical relevance of microparticles from platelets and megakaryocytes. Curr. Opin. Hematol. 17 578-584. doi: 10.1097/MOH.0b013e32833e77ee

Janowska-Wieczorek, A., Majka, M., Kijowski, J., Baj-Krzyworzeka, M., Reca, R., Turner, A. R., et al. (2001). Platelet-derived microparticles bind to hematopoietic stem/progenitor cells and enhance their engraftment. Blood 98, 3143-3149. doi: 10.1182/blood.V98.10.3143

Janowska-Wieczorek, A., Marquez-Curtis, L. A., Wysoczynski, M., and Ratajczak, M. Z. (2006). Enhancing effect of platelet-derived microvesicles on the invasive potential of breast cancer cells. Transfusion 46, 1199-1209. doi: 10.1111/j.1537-2995.2006.00871.x

Janowska-Wieczorek, A., Wysoczynski, M., Kijowski, J., Marquez-Curtis, L., Machalinski, B., Ratajczak, J., et al. (2005). Microvesicles derived from activated platelets induce metastasis and angiogenesis in lung cancer. Int. J. Cancer 113, 752-760. doi: 10.1002/ijc.20657

Jeppesen, D. K., Nawrocki, A., Jensen, S. G., Thorsen, K., Whitehead, B., Howard, K. A., et al. Ostenfeld, M.S. (2014). Quantitative proteomics of fractionated membrane and lumen exosome proteins from isogenic metastatic and nonmetastatic bladder cancer cells reveal differential expression of EMT factors. Proteomics 14, 699-712. doi: 10.1002/pmic.201300452

Ji, R., Zhang, B., Zhang, X., Xue, J., Yuan, X., Yan, Y., et al. (2015). Exosomes derived from human mesenchymal stem cells confer drug resistance in gastric cancer. Cell Cycle 14, 2473-2483. doi: 10.1080/15384101.2015.1005530

Johnstone, R. M., Adam, M., Hammond, J. R., Orr, L., and Turbide, C. (1987). Vesicle formation during reticulocyte maturation. Association of plasma membrane activities with released vesicles (exosomes). J. Biol. Chem. 262, 9412-9420.

Kalluri, R. (2016). The biology and function of exosomes in cancer. J. Clin. Invest. 126, 1208-1215. doi: 10.1172/JCI81135

Kamerkar, S., LeBleu, V. S., Sugimoto, H., Yang, S., Ruivo, C. F., Melo, S. A. et al. (2017). Exosomes facilitate therapeutic targeting of oncogenic KRAS in pancreatic cancer. Nature 546, 498-503. doi: 10.1038/nature22341

Kenific, C. M., Nogues, L., and Lyden, D. (2016). Pre-metastatic niche formation has taken its TOLL. Cancer Cell 30, 189-191. doi: 10.1016/j.ccell.2016.07.012

Kim, H. K., Song, K. S., Park, Y. S., Kang, Y. H., Lee, Y. J., Lee, K. R., et al. (2003). Elevated levels of circulating platelet microparticles, VEGF, IL-6 and RANTES in patients with gastric cancer: possible role of a metastasis predictor. Eur. J. Cancer 39, 184-191. doi: 10.1016/S0959-8049(02)00596-8

Kim, J. W., Wieckowski, E., Taylor, D. D., Reichert, T. E., Watkins, S., and Whiteside, T. L. (2005). Fas ligand - positive membranous vesicles isolated from sera of patients with oral cancer induce apoptosis of activated $\mathrm{T}$ lymphocytes. Clin. Cancer Res. 11, 1010-1020.

King, H. W., Michael, M. Z., and Gleadle, J. M. (2012). Hypoxic enhancement of exosome release by breast cancer cells. BMC Cancer 12:421. doi: 10.1186/1471-2407-12-421

Kitai, Y., Kawasaki, T., Sueyoshi, T., Kobiyama, K., Ishii, K. J., Zou, J., et al. (2017). DNA-containing exosomes derived from cancer cells treated with topotecan 
activate a STING-dependent pathway and reinforce antitumor immunity. J. Immunol. 198, 1649-1659. doi: 10.4049/jimmunol.1601694

Kong, J. N., He, Q., Wang, G., Dasgupta, S., Dinkins, M. B., Zhu, G., et al. (2015). Guggulsterone and bexarotene induce secretion of exosome-associated breast cancer resistance protein and reduce doxorubicin resistance in MDA-MB-231 cells. Int. J. Cancer 137, 1610-1620. doi: 10.1002/ijc.29542

Kowal, J., Arras, G., Colombo, M., Jouve, M., Morath, J. P., Primdal-Bengtson, B., et al. (2016). Proteomic comparison defines novel markers to characterize heterogeneous populations of extracellular vesicle subtypes. Proc. Natl. Acad. Sci. U.S.A. 113, E968-977. doi: 10.1073/pnas.1521230113

Kruger, S., Elmageed, Z. Y. A., Hawke, D. H., Wörner, P. M., Jansen, D. A., AbdelMageed, A. B., et al. (2014). Molecular characterization of exosome-like vesicles from breast cancer cells. BMC Cancer 14:44. doi: 10.1186/1471-2407-14-44

Kucharzewska, P., Christianson, H. C., Welch, J. E., Svensson, K. J., Fredlund, E., Ringner, M., et al. (2013). Exosomes reflect the hypoxic status of glioma cells and mediate hypoxia-dependent activation of vascular cells during tumor development. Proc. Natl. Acad. Sci. U.S.A. 110, 7312-7317. doi: 10.1073/pnas.1220998110

Lee, H. M., Choi, E.-J., Kim, J. H., Kim, T. D., Kim, Y.-K., Kang, C., et al. (2010). A membranous form of ICAM-1 on exosomes efficiently blocks leukocyte adhesion to activated endothelial cells. Biochem. Biophys. Res. Commun. 397, 251-256. doi: 10.1016/j.bbrc.2010.05.094

Li, C., Liu, D. R., Li, G. G., Wang, H. H., Li, X. W., Zhang, W., et al. (2015). CD97 promotes gastric cancer cell proliferation and invasion through exosomemediated MAPK signaling pathway. World J. Gastroenterol. 21, 6215-6228. doi: 10.3748/wjg.v21.i20.6215

Li, X., Wang, S., Zhu, R., Li, H., and Han, Q. (2016). Lung tumor exosomes induce a pro- inflammatory phenotype in mesenchymal stem cells via NFKB-TLR signaling pathway. J. Hematol. Oncol. 9:42. doi: 10.1186/s13045-016-0269-y

Li, Y., An, J., Huang, S., He, J., and Zhang, J. (2015). Esophageal cancer-derived microvesicles induce regulatory B cells. Cell Biochem. Funct. 33, 308-313. doi: $10.1002 / \mathrm{cbf} .3115$

Liu, C., Yu, S., Zinn, K., Wang, J., Zhang, L., Jia, Y., et al. (2006). Murine mammary carcinoma exosomes promote tumor growth by suppression of NK cell function. J. Immunol. 176, 1375-1385. doi: 10.4049/jimmunol.176.3.1375

Liu, Y., Gu, Y., Cao, X., Liu, Y., Gu, Y., and Cao, X. (2017). The exosomes in tumor immunity. Oncoimmunology. 4:e1027472. doi: 10.1080/2162402X.2015.1027472

Liu, Y., Gu, Y., Han, Y., Zhang, Q., Jiang, Z., Zhang, X., et al. (2016). Tumor exosomal RNAs promote lung pre-metastatic niche formation by activating alveolar epithelial TLR3 to recruit neutrophils. Cancer Cell 30, 243-256. doi: 10.1016/j.ccell.2016.06.021

Liu, Y., Xiang, X., Zhuang, X., Zhang, S., Liu, C., Cheng, Z., et al. (2010). Contribution of MyD88 to the tumor exosome-mediated induction of myeloid derived suppressor cells. Am. J. Pathol. 176, 2490-2499. doi: 10.2353/ajpath.2010.090777

Lötvall, J., Hill, A. F., Hochberg, F., Buzás, E. I., Di Vizio, D., Gardiner, C., et al. (2014). Minimal experimental requirements for definition of extracellular vesicles and their functions: a position statement from the International Society for Extracellular Vesicles. J. Extracell. Vesicles 3:26913. doi: $10.3402 /$ jev.v3.26913

Lukanidin, E., and Sleeman, J. P. (2012). Building the niche: the role of the S100 proteins in metastatic growth. Semin. Cancer Biol. 22, 216-225. doi: 10.1016/j.semcancer.2012.02.006

Lundholm, M., Schroder, M., Nagaeva, O., Baranov, V., Widmark, A., MinchevaNilsson, L., et al. (2014). Prostate tumor-derived exosomes down-regulate NKG2D expression on natural killer cells and CD8 + T Cells: mechanism of immune evasion. PLoS ONE 9:e108925. doi: 10.1371/journal.pone.0108925

Lv, L. H., Wan, Y. L., Lin, Y., Zhang, W., Yang, M., Li, G. Z., et al. (2012). Anticancer drugs cause release of exosomes with heat shock proteins from human hepatocellular carcinoma cells that elicit effective natural killer cell antitumor responses in vitro. J. Biol. Chem. 287, 15874-15885. doi: 10.1074/jbc.M112.340588

Ma, M., Chen, S., Liu, Z., Xie, H., Deng, H., Shang, S., et al. (2017). miRNA-221 of exosomes originating from bone marrow mesenchymal stem cells promotes oncogenic activity in gastric cancer. Onco. Targets. Ther. 10, 4161-4171. doi: 10.2147/OTT.S143315
Mantovani, A., Sica, A., Sozzani, S., Allavena, P., Vecchi, A., and Locati, M. (2004). The chemokine system in diverse forms of macrophage activation and polarization. Trends Immunol. 25, 677-686. doi: 10.1016/j.it.2004.09.015

Mao, L., Li, J., Chen, W. X., Cai, Y. Q., Yu, D. D., Zhong, S. L., et al. (2016). Exosomes decrease sensitivity of breast cancer cells to adriamycin by delivering microRNAs. Tumour Biol. 37, 5247-5256. doi: 10.1007/s13277-015-4402-2

Martinez, F. O., Sica, A., Mantovani, A., and Locati, M. (2008). Macrophage activation and polarization. Front. Biosci. 13, 453-461. doi: 10.2741/2692

Matsumoto, A., Takahashi, Y., Nishikawa, M., Sano, K., Morishita, M., Charoenviriyakul, C., et al. (2017). Accelerated growth of B16BL6 tumor in mice through efficient uptake of their own exosomes by B16BL6 cells. Cancer Sci. $108,1803-1810$. doi: $10.1111 /$ cas. 13310

Mayadas, T. N., Cullere, X., and Lowell, C. A. (2014). The multifaceted functions of neutrophils. Ann. Rev. Pathol. Mech. Dis. 9, 181-218. doi: 10.1146/annurev-pathol-020712-164023

Menck, K., Klemm, F., Gross, J. C., and Pukrop, T. (2013). Induction and transport of Wnt 5a during macrophage-induced malignant invasion is mediated by two types of extracellular vesicles. Oncotarget 4, 2057-2066. doi: 10.18632/oncotarget.1336

Merad, M., Sathe, P., Helft, J., Miller, J., and Mortha, A. (2013). The dendritic cell lineage: ontogeny and function of dendritic cells and their subsets in the steady state and the inflamed setting. Annu. Rev. Immunol. 31, 563-604. doi: 10.1146/annurev-immunol-020711-074950

Milia, A. F., Salis, M. B., Stacca, T., Pinna, A., Madeddu, P., Trevisani, M., et al. (2002). Protease-activated receptor-2 stimulates angiogenesis and accelerates hemodynamic recovery in a mouse model of hindlimb ischemia. Circ. Res. 91, 346-352. doi: 10.1161/01.RES.0000031958.92781.9E

Mincheva-Nilsson, L., and Baranov, V. (2014). Cancer exosomes and NKG2D receptor - ligand interactions: impairing NKG2D-mediated cytotoxicity and anti-tumour immune surveillance. Semin. Cancer Biol. 28, 24-30. doi: 10.1016/j.semcancer.2014.02.010

Morhayim, J., van de Peppel, J., Demmers, J. A., Kocer, G., Nigg, A. L., van Driel, M., et al. (2015). Proteomic signatures of extracellular vesicles secreted by nonmineralizing and mineralizing human osteoblasts and stimulation of tumor cell growth. FASEB J. 29, 274-285. doi: 10.1096/fj.14-261404

Morse, M. A., Garst, J., Osada, T., Khan, S., Hobeika, A., Clay, T. M., et al. (2005). A phase I study of dexosome immunotherapy in patients with advanced non-small cell lung cancer. J. Transl. Med. 3:9. doi: 10.1186/1479-5876-3-9

Morvan, M. G., and Lanier, L. L. (2015). NK cells and cancer: you can teach innate cells new tricks. Nat. Rev. Cancer 16, 7-19. doi: 10.1038/nrc.2015.5

Muller, L., Mitsuhashi, M., Simms, P., Gooding, W. E., and Whiteside, T. L. (2016). Tumor-derived exosomes regulate expression of immune function- related genes in human T cell subsets. Sci. Rep. 6:20254. doi: 10.1038/srep20254

Nagaraj, S., and Gabrilovich, D. I. (2007). Myeloid-derived suppressor cells. Adv. Exp. Med. Biol. 601, 213-223. doi: 10.1007/978-0-387-72005-0 22

Nouraee, N., Khazaei, S., Vasei, M., Razavipour, S. F., Sadeghizadeh, M., and Mowla, S. J. (2016). MicroRNAs contribution in tumor microenvironment of esophageal cancer. Cancer Biomark. 16, 367-376. doi: 10.3233/CBM-160575

O'Brien, J. R. (1955). The platelet-like activity of serum. Br. J. Haematol. 1, 223-228. doi: 10.1111/j.1365-2141.1955.tb05503.x

Ohnishi, K., Komohara, Y., Saito, Y., Miyamoto, Y., Watanabe, M., Baba, H., et al. (2013). CD169-positive macrophages in regional lymph nodes are associated with a favorable prognosis in patients with colorectal carcinoma. Cancer Sci. 104, 1237-1244. doi: 10.1111/cas.12212

Olumi, A. F., Grossfeld, G. D., Hayward, S. W., Carroll, P. R., Tlsty, T. D., and Cunha, G. R. (1999). Carcinoma-associated fibroblasts direct tumor progression of initiated human prostatic epithelium. Cancer Res. 59, 5002-5011.

Orimo, A., Gupta, P. B., Sgroi, D. C., Arenzana-Seisdedos, F., Delaunay, T., Naeem, R., et al. (2005). Stromal fibroblasts present in invasive human breast carcinomas promote tumor growth and angiogenesis through elevated SDF-1/CXCL12 secretion. Cell 121, 335-348. doi: 10.1016/j.cell.2005. 02.034

Palucka, K., and Banchereau, J. (2012). Cancer immunotherapy via dendritic cells. Nat. Rev. Cancer 12, 265-277. doi: 10.1038/nrc3258

Pan, L., Liang, W., Fu, M., Huang, Z. H., Li, X., Zhang, W., et al. (2017). Exosomes-mediated transfer of long noncoding RNA ZFAS1 promotes 
gastric cancer progression. J. Cancer Res. Clin. Oncol. 143, 991-1004. doi: 10.1007/s00432-017-2361-2

Park, J. E., Tan, H. S., Datta, A., Lai, R. C., Zhang, H., Meng, W., et al. (2010). Hypoxic tumor cell modulates its microenvironment to enhance angiogenic and metastatic potential by secretion of proteins and exosomes. Mol. Cell. Proteomics 9, 1085-1099. doi: 10.1074/mcp.M900381-MCP200

Peinado, H., Aleckovic, M., Lavotshkin, S., Matei, I., Costa-Silva, B., MorenoBueno, G., et al. (2012). Melanoma exosomes educate bone marrow progenitor cells toward a pro-metastatic phenotype through MET. Nat. Med. 18, 883-891. doi: $10.1038 / \mathrm{nm} .2753$

Peinado, H., Zhang, H., Matei, I. R., Costa-Silva, B., Hoshino, A., Rodrigues, G., et al. (2017). Pre-metastatic niches: organ-specific homes for metastases. Nat. Rev. Cancer 17, 302-317. doi: 10.1038/nrc.2017.6

Perone, M. J., Larregina, A. T., Shufesky, W. J., Papworth, G. D., Sullivan, M. L. G., Zahorchak, A. F., et al. (2006). Transgenic galectin-1 induces maturation of dendritic cells that elicit contrasting responses in naive and activated T cells. J. Immunol. 176, 7207-7220. doi: 10.4049/jimmunol.176.12.7207

Pfeffer, S. R. (2007). Unsolved mysteries in membrane traffic. Annu. Rev. Biochem. 76, 629-645. doi: 10.1146/annurev.biochem.76.061705.130002

Pitt, J. M., André, F., Amigorena, S., Soria, J. C., and Eggermont, A. (2016). Dendritic cell - derived exosomes for cancer therapy. J. Clin. Invest. 126, 1224-1232. doi: 10.1172/JCI81137

Pucci, F., Garris, C., Lai, C. P., Newton, A., Pfirschke, C., Engblom, C., et al. (2016). SCS macrophages suppress melanoma by restricting tumor-derived vesicle - B cell interactions. Science 352, 242-247. doi: 10.1126/science.aaf1328

Qin, X., Yu, S., Zhou, L., Shi, M., Hu, Y., Xu, X., et al. (2017). Cisplatin-resistant lung cancer cell-derived exosomes increase cisplatin resistance of recipient cells in exosomal miR-100-5p-dependent manner. Int. J. Nanomed. 12, 3721-3733. doi: 10.2147/IJN.S131516

Qu, J. L., Qu, X. J., Zhao, M. F., Teng, Y. E., Zhang, Y., Hou, K. Z., et al. (2009). Gastric cancer exosomes promote tumour cell proliferation through PI3K/Akt and MAPK/ERK activation. Dig. Liver Dis. 41, 875-880. doi: 10.1016/j.dld.2009.04.006

Quatromoni, J. G., and Eruslanov, E. (2012). Tumor-associated macrophages: function, phenotype, and link to prognosis in human lung cancer. Am. J. Transl. Res. 4, 376-389.

Raimondo, S., Saieva, L., Corrado, C., Fontana, S., Flugy, A., Rizzo, A., et al. (2015). Chronic myeloid leukemia-derived exosomes promote tumor growth through an autocrine mechanism. Cell Commun. Signal. 13:8. doi: 10.1186/s12964-015-0086-x

Ramteke, A., Ting, H., Agarwal, C., Mateen, S., Somasagara, R., Hussain, A., et al. (2015). Exosomes secreted under hypoxia enhance invasiveness and stemness of prostate cancer cells by targeting adherens junction molecules. Mol. Carcinog. 54, 554-565. doi: 10.1002/mc.22124

Rao, Q., Zuo, B., Lu, Z., Gao, X., You, A., Wu, C., et al. (2016). Tumorderived exosomes elicit tumor suppression in murine hepatocellular carcinoma models and humans in vitro. Hepatology 64, 456-472. doi: 10.1002/hep. 28549

Raposo, G., Nijman, H. W., Stoorvogel, W., Liejendekker, R., Harding, C. V., Melief, C. J., et al. (1996). B lymphocytes secrete antigen-presenting vesicles. J. Exp. Med. 183, 1161-1172. doi: 10.1084/jem.183.3.1161

Reiners, K. S., Dassler, J., Coch, C., and Strandmann, E. P. V. (2014). Role of exosomes released by dendritic cells and / or by tumor targets: regulation of NK cell plasticity. Front. Immunol. 5:91. doi: 10.3389/fimmu.2014.00091

Rialland, P., Lankar, D., Raposo, G., Bonnerot, C., and Hubert, P. (2006). BCRbound antigen is targeted to exosomes in human follicular lymphoma B-cells. Biol. Cell 98, 491-501. doi: 10.1042/BC20060027

Richards, K. E., Zeleniak, A. E., Fishel, M. L., Wu, J., Littlepage, L. E., and Hill, R. (2017). Cancer-associated fibroblast exosomes regulate survival and proliferation of pancreatic cancer cells. Oncogene 36, 1770-1778. doi: 10.1038/onc.2016.353

Robbins, P. D., and Morelli, A. E. (2014). Regulation of immune responses by extracellular vesicles. Nat. Rev. Immunol. 14, 195-208. doi: 10.1038/nri3622

Rogers, T. L., and Holen, I. (2011). Tumour macrophages as potential targets of bisphosphonates. J. Transl. Med. 9:177. doi: 10.1186/1479-5876-9-177

Saito, H., Takaya, S., Osaki, T., and Ikeguchi, M. (2013). Increased apoptosis and elevated Fas expression in circulating natural killer cells in gastric cancer patients. Gastric Cancer 16, 473-479. doi: 10.1007/s10120-012-0210-1
Sanchez, C. A., Andahur, E. I., Valenzuela, R., Castellon, E. A., Fulla, J. A., Ramos, C. G., et al. (2016). Exosomes from bulk and stem cells from human prostate cancer have a differential microRNA content that contributes cooperatively over local and pre-metastatic niche. Oncotarget 7, 3993-4008. doi: 10.18632/oncotarget.6540

Saunderson, S. C., Dunn, A. C., Crocker, P. R., and McLellan, A. D. (2014). CD169 mediates the capture of exosomes in spleen and lymph node. Blood 123, 208-216. doi: 10.1182/blood-2013-03-489732

Schiavoni, G., Gabriele, L., and Mattei, F. (2013). The tumor microenvironment: a pitch for multiple players. Front. Oncol. 3:90. doi: 10.3389/fonc.2013.00090

Segura, E., Nicco, C., Lombard, B., Véron, P., Raposo, G., Batteux, F., et al. (2005). ICAM-1 on exosomes from mature dendritic cells is critical for efficient naive T-cell priming. Blood 106, 216-223. doi: 10.1182/blood-2005-01-0220

Setti, M., Osti, D., Richichi, C., Ortensi, B., Del Bene, M., Fornasari, L., et al. (2015). Extracellular vesicle-mediated transfer of CLIC1 protein is a novel mechanism for the regulation of glioblastoma growth. Oncotarget 6, 31413-31427. doi: 10.18632/oncotarget.5105

Silva, T. A., Smuczek, B., Valadao, I. C., Dzik, L. M., Iglesia, R. P., Cruz, M. C., et al. (2016). AHNAK enables mammary carcinoma cells to produce extracellular vesicles that increase neighboring fibroblast cell motility. Oncotarget 7, 49998-50016. doi: 10.18632/oncotarget.10307

Skog, J., Würdinger, T., van Rijn, S., Meijer, D. H., Gainche, L., Sena-Esteves, M., et al. (2008). Glioblastoma microvesicles transport RNA and proteins that promote tumour growth and provide diagnostic biomarkers. Nat. Cell Biol. 10, 1470-1476. doi: 10.1038/ncb1800

Soderberg, A., Barral, A. M., Soderstrom, M., Sander, B., and Rosen, A. (2007). Redox-signaling transmitted in trans to neighboring cells by melanomaderived TNF-containing exosomes. Free Radic. Biol. Med. 43, 90-99. doi: 10.1016/j.freeradbiomed.2007.03.026

Soekmadji, C., Riches, J. D., Russell, P. J., Ruelcke, J. E., McPherson, S., Wang, C., et al. (2016). Modulation of paracrine signaling by CD9 positive small extracellular vesicles mediates cellular growth of androgen deprived prostate cancer. Oncotarget 8, 52237-52255. doi: 10.18632/oncotarget.11111

Sruthi, T. V., Edatt, L., Raji, G. R., K, H., Shankar, S. S., Shankar, V., et al. (2017). Horizontal transfer of miR-23a from hypoxic tumor cell colonies can induce angiogenesis. J. Cell Physiol. 233, 3498-3514. doi: 10.1002/jcp.26202

Svensson, K. J., Kucharzewska, P., Christianson, H. C., Skold, S., Lofstedt, T., Johansson, M. C., et al. (2011). Hypoxia triggers a proangiogenic pathway involving cancer cell microvesicles and PAR-2-mediated heparin-binding EGF signaling in endothelial cells. Proc. Natl. Acad. Sci. U.S.A. 108, 13147-13152. doi: 10.1073/pnas.1104261108

Syn, N., Wang, L., Sethi, G., Thiery, J.-P, and p., Goh, B.-C. (2016). Exosome-mediated metastasis: from epithelial - mesenchymal transition to escape from immunosurveillance. Trends Pharmacol. Sci. 37, 606-617. doi: 10.1016/j.tips.2016.04.006

Szczepanski, M. J., Szajnik, M., Welsh, A., Whiteside, T. L., and Boyiadzis, M. (2011). Blast-derived microvesicles in sera from patients with acute myeloid leukemia suppress natural killer cell function via membraneassociated transforming growth factor- $\beta$ 1. Haematologica 96, 1302-1309. doi: 10.3324/haematol.2010.039743

Takahashi, K., Yan, I. K., Kogure, T., Haga, H., and Patel, T. (2014). Extracellular vesicle-mediated transfer of long non-coding RNA ROR modulates chemosensitivity in human hepatocellular cancer. FEBS Open Bio 4, 458-467. doi: 10.1016/j.fob.2014.04.007

Takasugi, M., Okada, R., Takahashi, A., Virya Chen, D., Watanabe, S., and Hara, E. (2017). Small extracellular vesicles secreted from senescent cells promote cancer cell proliferation through EphA2. Nat. Commun. 8:15729. doi: 10.1038/ncomms15728

Taverna, S., Flugy, A., Saieva, L., Kohn, E. C., Santoro, A., Meraviglia, S., et al. (2012). Role of exosomes released by chronic myelogenous leukemia cells in angiogenesis. Int. J. Cancer 130, 2033-2043. doi: 10.1002/ijc.26217

Taylor, D. D., and Gercel-taylor, C. (2011). Exosomes / microvesicles: mediators of cancer-associated immunosuppressive microenvironments. Semin. Immunopathol. 33, 441-454. doi: 10.1007/s00281-010-0234-8

Taylor, D. D., Gerçel-Taylor, C., Lyons, K. S., Stanson, J., and Whiteside, T. L. (2003). T-cell apoptosis and suppression of T-cell receptor/CD3-zeta by Fas ligand-containing membrane vesicles shed from ovarian tumors. Clin. Cancer Res. 9, 5113-5119. 
Temme, S., Eis-Hubinger, A. M., McLellan, A. D., and Koch, N. (2010). The herpes simplex virus-1 encoded glycoprotein B diverts HLA-DR into the exosome pathway. J. Immunol. 184, 236-243. doi: 10.4049/jimmunol.0902192

Théry, C., Boussac, M., Véron, P., Ricciardi-Castagnoli, P., Raposo, G., Garin, J., et al. (2001). Proteomic analysis of dendritic cell-derived exosomes: a secreted subcellular compartment distinct from apoptotic vesicles. J. Immunol. 166, 7309-7318. doi: 10.4049/jimmunol.166.12.7309

Thompson, C. A., Purushothaman, A., Ramani, V. C., Vlodavsky, I., and Sanderson, R. D. (2013). Heparanase regulates secretion, composition, and function of tumor cell-derived exosomes. J. Biol. Chem. 288, 10093-10099. doi: 10.1074/jbc.C112.444562

Tian, H., and Li, W. (2017). Dendritic cell-derived exosomes for cancer immunotherapy: hope and challenges. Ann. Transl. Med. 5, 221-221. doi: 10.21037/atm.2017.02.23

Tomasek, J. J., Gabbiani, G., Hinz, B., Chaponnier, C., and Brown, R. A. (2002). Myofibroblasts and mechano-regulation of connective tissue remodelling. Nat. Rev. Mol. Cell Biol. 3, 349-363. doi: 10.1038/nrm809

Tominaga, N., Kosaka, N., Ono, M., Katsuda, T., Yoshioka, Y., Tamura, K., et al. (2015). Brain metastatic cancer cells release microRNA-181c-containing extracellular vesicles capable of destructing blood-brain barrier. Nat. Commun. 6, 6716. doi: $10.1038 /$ ncomms7716

Toth, B., Liebhardt, S., Steinig, K., Ditsch, N., Rank, A., Bauerfeind, I., et al. (2008). Platelet-derived microparticles and coagulation activation in breast cancer patients. Thromb. Haemost. 100, 663-669. doi: 10.1160/TH07-10-0602

Treps, L., Perret, R., Edmond, S., Ricard, D., and Gavard, J. (2017). Glioblastoma stem-like cells secrete the pro-angiogenic VEGF-A factor in extracellular vesicles. J. Extracell. Vesicles 6:1359479. doi: 10.1080/20013078.2017.1359479

Umezu, T., Ohyashiki, K., Kuroda, M., and Ohyashiki, J. H. (2013). Leukemia cell to endothelial cell communication via exosomal miRNAs. Oncogene 32, 2747-2755. doi: 10.1038/onc.2012.295

Ung, T. H., Madsen, H. J., Hellwinkel, J. E., Lencioni, A. M., and Graner, M. W. (2014). Exosome proteomics reveals transcriptional regulator proteins with potential to mediate downstream pathways. Cancer Sci. 105, 1384-1392. doi: $10.1111 /$ cas. 12534

Valenti, R., Huber, V., Filipazzi, P., Pilla, L., Sovena, G., Villa, A., et al. (2006). Human tumor-released microvesicles promote the differentiation of myeloid cells with transforming growth factor-beta-mediated suppressive activity on $\mathrm{T}$ lymphocytes. Cancer Res. 66, 9290-9298. doi: 10.1158/0008-5472.CAN-06-1819

Voloshin, T., Fremder, E., and Shaked, Y. (2014). Small but mighty: microparticles as mediators of tumor progression. Cancer Microenviron. 7, 11-21. doi: $10.1007 /$ s12307-014-0144-8

Wang, J., Hendrix, A., Hernot, S., Lemaire, M., De Bruyne, E., Van Valckenborgh, E., et al. (2014). Bone marrow stromal cell-derived exosomes as communicators in drug resistance in multiple myeloma cells. Blood 124, 555-566. doi: 10.1182/blood-2014-03-562439

Wang, J., Veirman, K. D., Faict, S., Frassanito, M. A., Ribatti, D., and Vacca, A. (2016). Multiple myeloma exosomes establish a favourable bone marrow microenvironment with enhanced angiogenesis and immunosuppression. J. Pathol. 239, 162-173. doi: 10.1002/path.4712

Wculek, S. K., and Malanchi, I. (2015). Neutrophils support lung colonization of metastasis-initiating breast cancer cells. Nature 528, 413-417. doi: 10.1038/nature16140

Webber, J. P., Spary, L. K., Sanders, A. J., Chowdhury, R., Jiang, W. G., Steadman, R., et al. (2015). Differentiation of tumour-promoting stromal myofibroblasts by cancer exosomes. Oncogene 34, 290-302. doi: 10.1038/onc. 2013.560

Webber, J., Steadman, R., Mason, M. D., Tabi, Z., and Clayton, A. (2010). Cancer exosomes trigger fibroblast to myofibroblast differentiation. Cancer Res. 70, 9621-9630. doi: 10.1158/0008-5472.CAN-10-1722

Wei, M., Yang, T., Chen, X., Wu, Y., Deng, X., He, W., et al. (2017). Malignant ascites-derived exosomes promote proliferation and induce carcinomaassociated fibroblasts transition in peritoneal mesothelial cells. Oncotarget 8, 42262-42271. doi: 10.18632/oncotarget.15040

Wei, Y., Lai, X., Yu, S., Chen, S., Ma, Y., Zhang, Y., et al. (2014). Exosomal miR-221/222 enhances tamoxifen resistance in recipient ER-positive breast cancer cells. Breast Cancer Res. Treat. 147, 423-431. doi: 10.1007/s10549-0143037-0
Whiteside, T. L. (2013). Immune modulation of T-cell and NK (natural killer) cell activities by TEXs (tumour-derived exosomes). Biochem. Soc. Trans. 41, 245-251. doi: 10.1042/BST20120265

Wieckowski, E. U., Visus, C., Szajnik, M., Szczepanski, M. J., Storkus, W. J., and Theresa, L. (2009). Tumor-derived microvesicles promote regulatory T cell expansion and induce apoptosis in tumor-reactive activated CD8 + T lymphocytes. J. Immunol. 183, 3720-3730. doi: 10.4049/jimmunol.0900970

Witwer, K. W., Buzás, E. I., Bemis, L. T., Bora, A., Lässer, C., Lötvall, J., et al. (2013). Standardization of sample collection, isolation and analysis methods in extracellular vesicle research. J. Extracell. Vesicles 2:20360. doi: $10.3402 /$ jev.v2i0.20360

Wolf, P. (1967). The nature and significance of platelet products in human plasma. Br. J. Haematol. 13, 269-288. doi: 10.1111/j.1365-2141.1967.tb08741.x

Wu, L., Zhang, X., Zhang, B., Shi, H., Yuan, X., Sun, Y., et al. (2016). Exosomes derived from gastric cancer cells activate NF-kappaB pathway in macrophages to promote cancer progression. Tumour Biol. 37, 12169-12180. doi: 10.1007/s13277-016-5071-5

Wu, Q., Wu, X., Ying, X., Zhu, Q., Wang, X., Jiang, L., et al. (2017). Suppression of endothelial cell migration by tumor associated macrophage-derived exosomes is reversed by epithelial ovarian cancer exosomal lncRNA. Cancer Cell Int. 17:62. doi: 10.1186/s12935-017-0430-X

Xiang, X., Poliakov, A., Liu, C., Liu, Y., Deng, Z. B., and Wang, J. G. (2009). Induction of myeloid-derived suppressor cells by tumor exosomes. Int. J. Cancer 2633, 2621-2633. doi: 10.1002/ijc.24249

Xiao, X., Yu, S., Li, S., Wu, J., Ma, R., Cao, H., et al. (2014). Exosomes: decreased sensitivity of lung cancer A549 cells to cisplatin. PLoS ONE 9:e89534. doi: 10.1371/journal.pone.0089534

Xue, J., Schmidt, S. V., Sander, J., Draffehn, A., Krebs, W., Quester, I., et al. (2014). Transcriptome-based network analysis reveals a spectrum model of human macrophage activation. Immunity 40, 274-288. doi: 10.1016/j.immuni.2014.01.006

Yang, C., Chalasani, G., Ng, Y.-H., and Robbins, P. D. (2012). Exosomes released from mycoplasma infected tumor cells activate inhibitory B cells. PLoS ONE 7:e36138. doi: 10.1371/journal.pone.0036138

Yang, C., Kim, S.-H., Bianco, N. R., and Robbins, P. D. (2011). Tumorderived exosomes confer antigen-specific immunosuppression in a murine delayed-type hypersensitivity model. PLoS ONE 6:e22517. doi: 10.1371/journal.pone.0022517

Yang, L., Wu, X. H., Wang, D., Luo, C. L., and Chen, L. X. (2013). Bladder cancer cell-derived exosomes inhibit tumor cell apoptosis and induce cell proliferation in vitro. Mol. Med. Rep. 8, 1272-1278. doi: 10.3892/mmr.2013.1634

Yang, S. J., Wang, D. D., Li, J., Xu, H. Z., Shen, H. Y., Chen, X., et al. (2017). Predictive role of GSTP1-containing exosomes in chemotherapy-resistant breast cancer. Gene 623, 5-14. doi: 10.1016/j.gene.2017.04.031

Yang, Y., Xiu, F., Cai, Z., Wang, J., Wang, Q., Fu, Y., et al., (2007). Increased induction of antitumor response by exosomes derived from interleukin2 gene-modified tumor cells. J. Cancer Res. Clin. Oncol. 133, 389-399. doi: 10.1007/s00432-006-0184-7

Ye, S. B., Li, Z. L., Luo, D. H., Huang, B. J., and Chen, Y. S. (2014). Tumorderived exosomes promote tumor progression and T-cell dysfunction through the regulation of enriched exosomal microRNAs in human nasopharyngeal carcinoma. Oncotarget 5, 5439-5452. doi: 10.18632/oncotarget.2118

Yin, Y., Cai, X., Chen, X., Liang, H., Zhang, Y., Li, J., et al. (2014). Tumor-secreted miR-214 induces regulatory T cells: a major link between immune evasion and tumor growth. Cell Res. 24, 1164-1180. doi: 10.1038/cr.2014.121

Ying, X., Wu, Q., Wu, X., Zhu, Q., Wang, X., and Jiang, L. (2016). Epithelial ovarian cancer-secreted exosomal miR-222-3p induces polarization of tumor-associated macrophages. Oncotarget 7, 43076-43087. doi: 10.18632/oncotarget.9246

Yoshimura, A., Sawada, K., and Kimura, T. (2017). Is the exosome a potential target for cancer immunotherapy? Ann. Transl. Med. 5:117. doi: 10.21037/atm.2017.01.47

Yoshizaki, T., Kondo, S., Wakisaka, N., Murono, S., Endo, K., Sugimoto, H., et al. (2013). Pathogenic role of Epstein-Barr virus latent membrane protein1 in the development of nasopharyngeal carcinoma. Cancer Lett. 337, 1-7. doi: 10.1016/j.canlet.2013.05.018

You, Y., Shan, Y., Chen, J., Yue, H., You, B., Shi, S., et al. (2015). Matrix metalloproteinase 13-containing exosomes promote nasopharyngeal 
carcinoma metastasis. Cancer Sci. 106, 1669-1677. doi: 10.1111/cas. 12818

Yu, D. D., Wu, Y., Zhang, X. H., Lv, M. M., Chen, W. X., Chen, X., et al. (2016). Exosomes from adriamycin-resistant breast cancer cells transmit drug resistance partly by delivering miR-222. Tumour Biol. 37, 3227-3235. doi: 10.1007/s13277-015-4161-0

Yue, S., Mu, W., Erb, U., and Zoller, M. (2015). The tetraspanins CD151 and Tspan 8 are essential exosome components for the crosstalk between cancer initiating cells and their surrounding. Oncotarget 6, 2366-2384. doi: 10.18632/oncotarget.2958

Yuen, G. J., Demissie, E., and Pillai, S. (2016). B lymphocytes and cancer: a lovehate relationship. Trends Cancer 2, 747-757. doi: 10.1016/j.trecan.2016.10.010

Zhao, H., Yang, L., Baddour, J., Achreja, A., Bernard, V., Moss, T., et al. (2016). Tumor microenvironment derived exosomes pleiotropically modulate cancer cell metabolism. Elife 5:e10250. doi: 10.7554/eLife.10250

Zheng, P., Chen, L., Yuan, X., Luo, Q., Liu, Y., Xie, G., et al. (2017). Exosomal transfer of tumor-associated macrophage-derived miR-21 confers cisplatin resistance in gastric cancer cells. J. Exp. Clin. Cancer Res. 36:53. doi: 10.1186/s13046-017-0528-y

Zhou, M., Chen, J., Zhou, L., Chen, W., Ding, G., and Cao, L. (2014). Pancreatic cancer derived exosomes regulate the expression of TLR4 in dendritic cells via miR-203. Cell. Immunol. 292, 65-69. doi: 10.1016/j.cellimm.2014.09.004

Zhou, W., Fong, M. Y., Min, Y., Somlo, G., Liu, L., Palomares, M. R., et al. (2014). Cancer-secreted miR-105 destroys vascular endothelial barriers to promote metastasis. Cancer Cell 25, 501-515. doi: 10.1016/j.ccr.2014. 03.007
Zhu, L., Kalimuthu, S., Gangadaran, P., Oh, J. M., Lee, H. W., Baek, S. H., et al. (2017). Exosomes derived from natural killer cells exert therapeutic effect in melanoma. Theranostics 7, 2732-2745. doi: 10.7150/thno.18752

Zhu, W., Huang, L., Li, Y., Zhang, X., Gu, J., Yan, Y., et al. (2012). Exosomes derived from human bone marrow mesenchymal stem cells promote tumor growth in vivo. Cancer Lett. 315, 28-37. doi: 10.1016/j.canlet.2011.10.002

Zitvogel, L., Regnault, A., Lozier, A., Wolfers, J., Flament, C., Tenza, D. et al. (1998). Eradication of established murine tumors using a novel cell-free vaccine: dendritic cell-derived exosomes. Nat. Med. 4, 594-600. doi: 10.1038/nm0598-594

Zmigrodzka, M., Guzera, M., Miskiewicz, A., Jagielski, D., and Winnicka, A. (2016). The biology of extracellular vesicles with focus on platelet microparticles and their role in cancer development and progression. Tumour Biol. 37, 14391-14401. doi: 10.1007/s13277-016-5358-6

Conflict of Interest Statement: The authors declare that the research was conducted in the absence of any commercial or financial relationships that could be construed as a potential conflict of interest.

Copyright (c) 2018 Maia, Caja, Strano Moraes, Couto and Costa-Silva. This is an open-access article distributed under the terms of the Creative Commons Attribution License (CC BY). The use, distribution or reproduction in other forums is permitted, provided the original author(s) and the copyright owner are credited and that the original publication in this journal is cited, in accordance with accepted academic practice. No use, distribution or reproduction is permitted which does not comply with these terms. 